\title{
The Effect of Heat Shocks and Freezing-Thawing Cycles on the Mechanical Properties of Natural Building Stones
}

\author{
Mohammad-Taghi Hamzaban ${ }^{1, *}$, Ismail Sedat Büyüksağiş ${ }^{2}$, Ali Touranchehzadeh ${ }^{1}$ and \\ Milad Manafi ${ }^{1}$
}

\author{
${ }^{1}$ Mining Engineering Faculty, Sahand University of Technology, Tabriz, Iran \\ ${ }^{2}$ Department of Mining Engineering, Afyon Kocatepe University, Afyonkarahisar, Turkey
}

\begin{abstract}
The damage to rock masses due to the action of freezing is one of the most important factors in the development of landscapes, the performance of civil structures, and the efficiency of mining operations. In this research paper, the effect has been studied on the physical and mechanical performance of seven different natural building rock samples. The testing program included an experimental study on both dry and saturated intact rock samples and therefore, the effect of saturation on the extent of damage on the tested samples has been discussed as well. Based on the obtained results, freezing-thawing cycles increase the porosity of rock samples and decrease the values of P-wave velocity, uniaxial compressive strength, elastic modulus, and Brazilian tensile strength. Moreover, the behavior of different rock types differs to some extent when exposed to weathering cycles under dry and saturated conditions. A multivariate linear regression analysis was used to predict the changes in the physical and mechanical properties of different rock types. It was been shown that with some cautions, the obtained correlations can be generalized for practical cases and can be used to predict the change of rock physical and mechanical properties during the lifetime of rock engineering projects. Such predictions have a high potential of applicability in quite different types of natural stone applications in cold climates. From the stability of structures created in rock materials to the durability of structures created by different natural stones.
\end{abstract}

Keywords: Building Stone, Physical Properties, Mechanical Properties, Laboratory Tests, Freezing-Thawing, Weathering.

\section{INTRODUCTION}

For many years, the damage on rock masses due to the action of freezing, or frost cracking, has been an important subject to geomorphologists. In the development of landscapes in periglacial environments as well as in glaciated terrains, the action of frost has been considered to be of paramount importance [1]. In permafrost, it is vital to conduct applied research for evaluating the effect of freezing-thawing on the stability of developed railway and road trenches, the efficiency of mining operations, and the lifetime of civil structures [2]. In the cold climate mountainous areas, the natural freezing-thawing processes are the main cause for slope instabilities, slope deterioration, and weathering $[3,4]$. As the ground undergoes freezethaw cycles, the volume of pore water is altered in which leads to deformation. For the storage of LNG (liquefied natural gas), the working temperature of semi-ground storage tanks is generally is about $-162^{\circ} \mathrm{C}$. Therefore, this necessitates an extensive understanding of the frozen ground behavior including occurred deformation, temperature distribution, structure-frozen ground interaction (in-ground storage tank), etc. for designing and safety assessing of the storage system [5]. Sun et al. (2018) have reported the use of cyclic cryogenic cracking based on the effect of freezing-thawing to break coal seams to increase the efficiency of gas drainage as the result of permeability

Address correspondence to this article at the Mining Engineering Faculty, Sahand University of Technology, Tabriz, Iran; Tel: +984133459232; Fax: +984133444312; E-mail: hamzaban@sut.ac.ir increase [6]. In the tunnels, which are located in cold regions, different damages extensions due to the effect of frost action have been reported [7]. In some tunnels, frost heave forces have led to fissures in their lining, which negatively affected the transportation flow $[8,9]$. Zhang et al. (2004) reported the use of computerized tomography (CT) equipment for describing the characteristics of the propagation of damages inside the surrounding rock of a cold-region tunnel [10].

In cold environments, the simulation of frost-induced deterioration on rock materials has been a major investigation avenue in the attempts to clarify the rates and mechanisms of rock breakdown [11]. Taber (1950) emphasized that ice crystals growth inside soil and rock materials, accompanied with the pressure development, is controlled by different several factors, including the pore spaces size, particles size, permeability, resistance against to the expansion of voids, cooling rate, and the amount of available water [12]. Hall (1988) showed that in a one-directional freeze process inside an open system, the rock saturation degree affects the amount of weathering that will take place. Similarly, Chen et al. (2004) revealed that if the initial saturation degree exceeds $70 \%$, the welded tuff samples will damage significantly [13]. The reported critical saturation degree for ignimbrite and andesite samples is $75 \%$ [14]. When the rock samples are very close to the water saturation state, passing the $0^{\circ} \mathrm{C}$ threshold causes a considerable expansion in the system volume [15]. Nevertheless, based on the collected data from the northern parts of Canada, Hall (2007) indicated that the freezing temperature can vary 
substantially, even in the same site [16]. Some authors considered that in cold-humid regions, the dominant factor in rock breakdown is the action of freeze-thaw and other processes are negligible [17]. However, performing several thermal stress events, Hall (2004) suggested that the rock weathering process in cold climates is a synergistic combination of the different mechanisms of chemical and mechanical weathering [18]. Mutlutürk et al. (2004) postulated a first-order process model for the weathering of rocks under freezing-thawing and heat-cooling cycles [19]. The reported results by Nicholson et al. (2000) suggest that the coupled relationship between rock flaws, rock strength, and textural properties, exerts the largest influence on deterioration mode. During a freeze-thaw weathering process, preliminary fractures, void spaces, and inferior lithological boundaries frequently happen together with the concentrations of deterioration. Strong rock formations such as metasediment materials and crystalline limestones tend to exhibit fracturing along preferential distinct linear weakness planes such as stylolites, mineral veins, and preliminary fractures. In contrast, in weak rocks, such as low-density chalk, breaking occurs randomly without any pre-existing flaw [20]. In addition to rock type, saturation degree, and temperature range, the water chemistry has a considerable effect on the deterioration rates. Using different solutions during freezing-thawing cycles, it has been shown that when the pore chemical solution changes, the resulting quality of samples due to the effect of freeze-thaw cycles differs [21-23].

Walder and Hallet presented (1985) a model based on the fundamental postulate that frost-induced degradation of porous rock results from the slow growth of cracks pressurized internally by ice. Considering continuum mechanics fundamental laws, i.e., mass, momentum, and energy conservation along with mixtures theory, Exadaktylos presented a coupled freezing-thawing model for saturated porous materials, including soils and rocks [24]. Using continuum damage mechanics theory, Zhang et al. (2019) and Fang et al. (2019) constructed a model to describe rock damage under loading and simulated freeze-thaw cycles [25]. The model can reflect the regulation between the internal freeze-thaw damage mechanism and some selected physical variables [26]. In addition to the intact rock, Chen et al. (2020) represented a mechanism for freezing-thawing damage and the degradation of fractured rock masses considering the damage mechanics theory and the results of laboratory experiments [27]. Based on the results reported by Liu et al. (2015), the freeze-thaw induces damage of rock materials can be considered equivalent to fatigue damage under triaxial tensile stress due to the effect of ice pressure in pore spaces. The model was used for rock samples which have different porosities and different degree of water-saturation [28].

Neaupane et al. (1999) described the application of a thermo-hydro-mechanical coupled numerical model for simulating the laboratory experiments of freezing and thawing. Kang et al. (2013) implemented a thermo-hydro-mechanical (THM) process into a three-dimensional finite-difference code to simulate the cooling test of an underground cavern for liquefied natural gas storage at very low temperatures [29]. Huang et al. (2018) proposed a statistical constitutive model to express the damage of loaded rock materials under freeze-thaw cycles. Considering the coupled thermo-hydro-mechanical condition, the model was implemented into a finite element model to study the stability of a cold region tunnel [30].

Hale and Shakoor (2003) reported that the uniaxial compressive strength (UCS) of some sandstones diminishes during freezing and thawing. Similar results on the effect of freeze-thaw cycles on the strength of different rock types have been reported by different authors [13, 31]. The reported results also indicated that during multiple freeze-thaw cycles, significant deterioration occurs over a specific range of porosity values [32]. Performing laboratory tests, Yavuz et al. (2006) studied the effect of physical weathering due to freeze-thaw and thermal shock on index properties, P-wave velocity, uniaxial compressive strength, and Schmidt hardness. They revealed that the index properties of deteriorated rock samples treated with freeze-thaw and thermal shock decrease in varying levels concerning initial values. They developed a predicting model by multiple regression analysis to explain the observed changes of a deteriorated rock considering its initial property and porosity of rock with the coefficients for a specific index property [33]. The effect of the microstructural changes due to thermal treatments on the macroscopic properties of different rock samples such as granitic rocks [34, 35], red sandstone, and shale [36-38], biotite granite [39], limestone [40], different ignimbrites [41], diorite, basalt, and tuff [42], different sandstones [43-47], andesite [48], pyroclastic rocks [49], arenite, limestone, subarkose, sandstone, and mudstone [50], Carboniferous slates [51], loess [52], and calc-schist [22] has been reported by different authors. Demirdag (2013) compared the performance of filled and unfilled travertine against freezing-thawing and thermal shocks. Travertine rock materials usually include many pores, which appear during the rock formation process, in their natural structures. Sometimes white Portland cement, calcite, and other coloring agents are used to fill these pores to increase the performance of the rock materials as a 
building stone. The results showed that the freezingthawing and thermal shock cycles have a significant effect on the strength values of filled travertine comparing unfilled similar travertine types [53]. The results of direct shear tests on the jointed rock samples have revealed that the effect of freeze-thaw cycles on joint cohesion is more than the effect on joint friction angle. However, the effect is seemed to be different between soft rocks and hard ones [54]. Moreover, it has been shown that the effect of freeze-thaw cycle on the shear strength of high persistency joints is greater than the effect on the joints with low persistency [55].

In places where a cold winter climate is experienced and in countries close to the polar regions, the natural stones used in the exterior cladding of the buildings are broken and fragmented as a result of the freezing-thawing processes (Figure 1). The resulting fragments falling from very high elevations have the potential of great damage to the environment and pedestrians below. This causes great compensations to be paid. Therefore, the frost resistance of natural stones to be used in exterior cladding in high-rise buildings and skyscrapers must be determined with some standards [56, 57]. Users and contractors choose natural stones to be used in cold climates according to these standard test results.

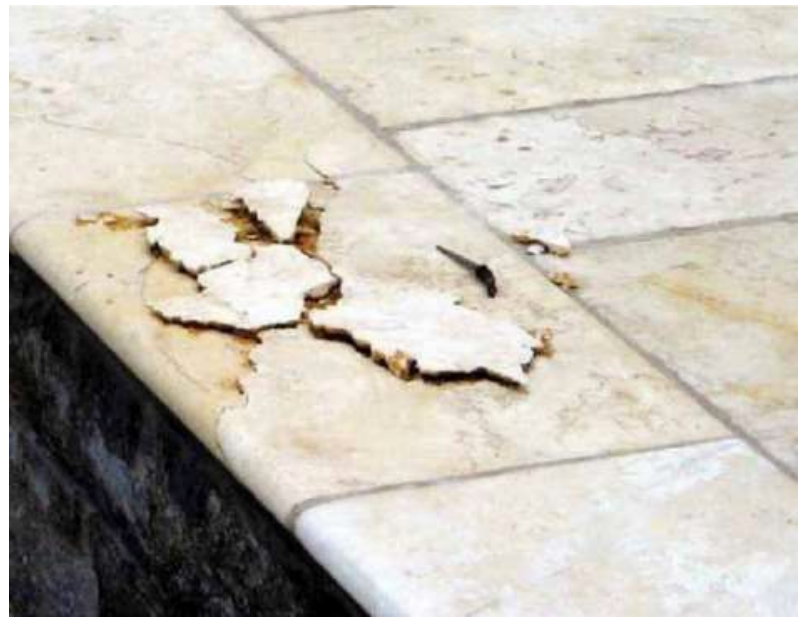

Figure 1: Damages due to saturated freeze - thaw cycling of a limestone paving [58]

Due to the importance of thermal shocks and freezing-thawing cycles on the mechanical properties of rock material, the effect has been studied in this paper. The testing program included an experimental study on both dry and saturated intact rock samples. Therefore, the effect of saturation on the extent of damages on the tested samples has been discussed as well.

\section{MATERIALS AND METHODS}

In this research paper, the effect of the numbers of freezing-thawing cycles on the mechanical properties of some intact rock samples, which are mostly used as natural building stones, were studied considering the recommended testing procedures of ISRM [59]. The freezing-thawing cycles, in the temperature span of $-32^{\circ} \mathrm{C}$ to $+40^{\circ} \mathrm{C}$, were simulated using a freezer and an oven (Figure 2). Both the freezer and oven were equipped with analog and digital temperature gauges respectively and they were capable to preserve the required temperature during the performed thermal treatments. Each cycle includes the following steps:

1. Placing the samples in the oven, which its temperature increases gradually up to $+40^{\circ} \mathrm{C}$. The samples were kept at this temperature for $23 \mathrm{hrs}$.

2. Keeping the samples in the laboratory atmosphere for one hour to prevent severe thermal shocks. The saturated samples were kept submerged in water at this stage. Moreover, both the freezer and oven turned off with opened caps to establish a temperature balance between their chambers and laboratory atmosphere during this one-hour step.

3. Placing the samples in the freezer, which its temperature decreases gradually down to $-32^{\circ} \mathrm{C}$. The samples were kept at this temperature for $23 \mathrm{hrs}$.

4. Keeping the samples in the laboratory atmosphere for another one-hour time interval as described in step 2.

Therefore, each cycle takes two days. Figure 3 shows the history of the temperature changes schematically during a single cycle. The testing program was performed on both dry and saturated samples. For the dry set of samples, the samples dried in the oven before starting the heat treatment cycles. The saturated set of rock samples passed a saturation phase based on the ISRM (International Society for Rock Mechanics) recommendations [59] before freezing-thawing cycles. The saturated samples were kept submerged in a water container during the heating phase to avoid drying. Testing samples include seven types of different intact rocks: two kinds of andesite with different mechanical properties, basalt, granite, onyx, sandstone, and travertine. Considering ISRM recommendations for rock sample preparation, a total of 90 core samples were prepared for each rock type (Figure 4). The core samples were divided into five groups. The first group was tested immediately after preparation (after saturation phase for saturated samples). The second group experienced two freezing-thawing cycles, which took 4 days, before testing. The count of cycles was doubled for the next 


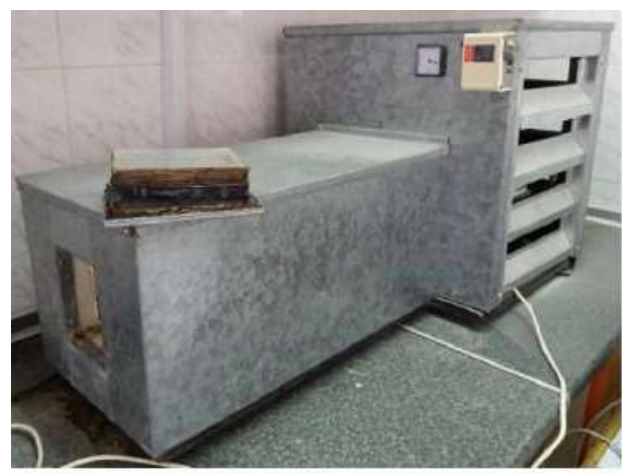

(a)

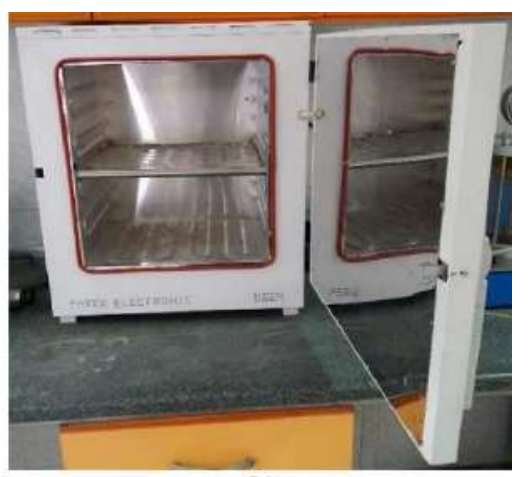

(b)

Figure 2: a) the freezer and b) the oven used to simulate freezing and thawing cycles.

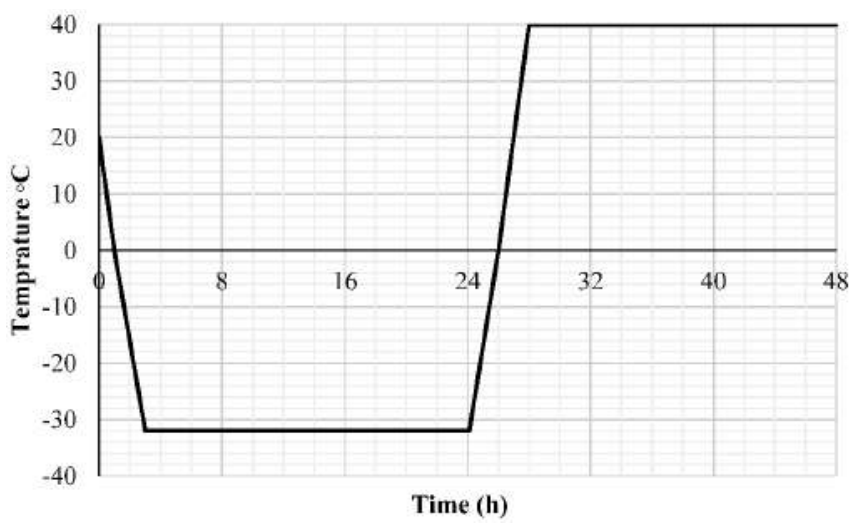

Figure 3: The schematic history of temperature changes during a single freeze - thaw cycle.

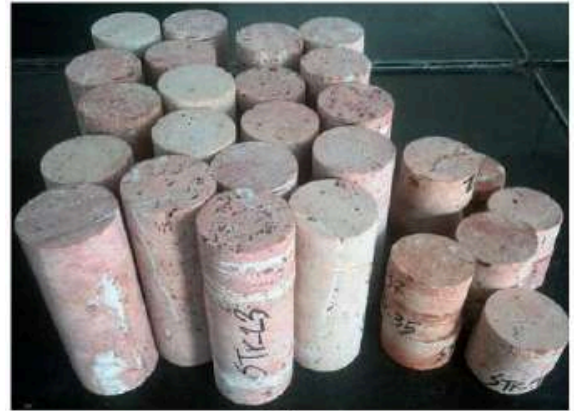

(a)

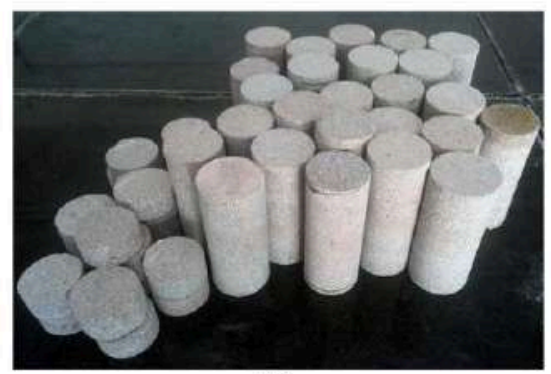

(c)

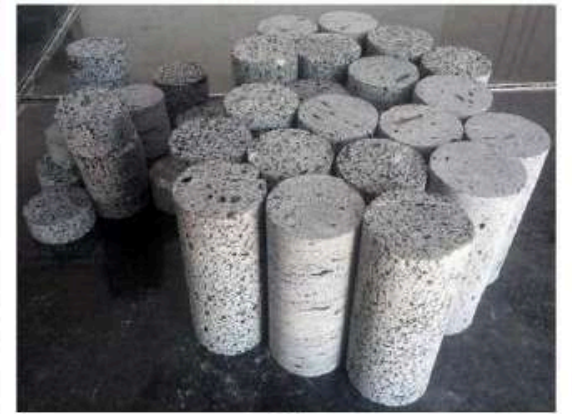

(b)

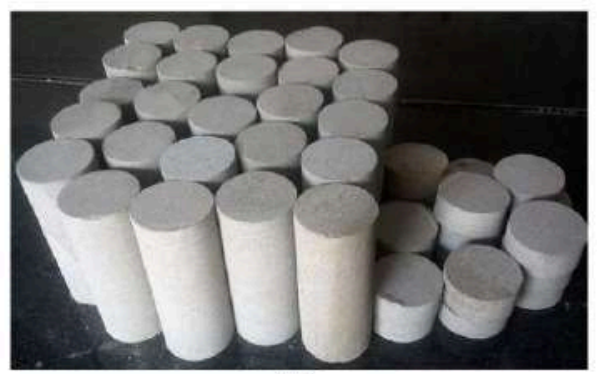

(d)

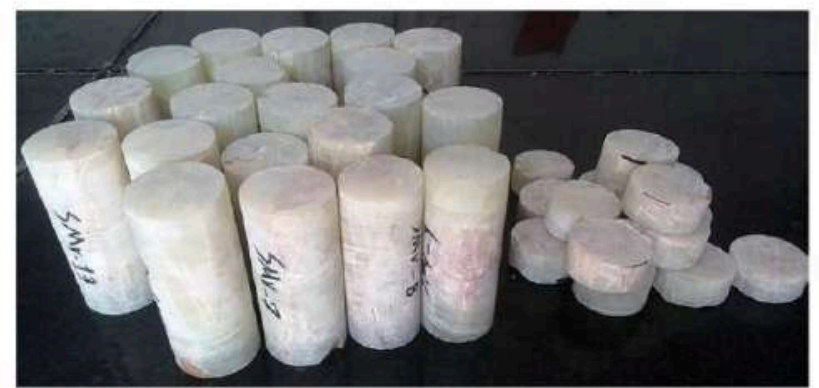

(e)

Figure 4: Photos of some prepared rock samples: a) travertine, b) basalt, c) andesite, d) sandstone, and e) onyx. 


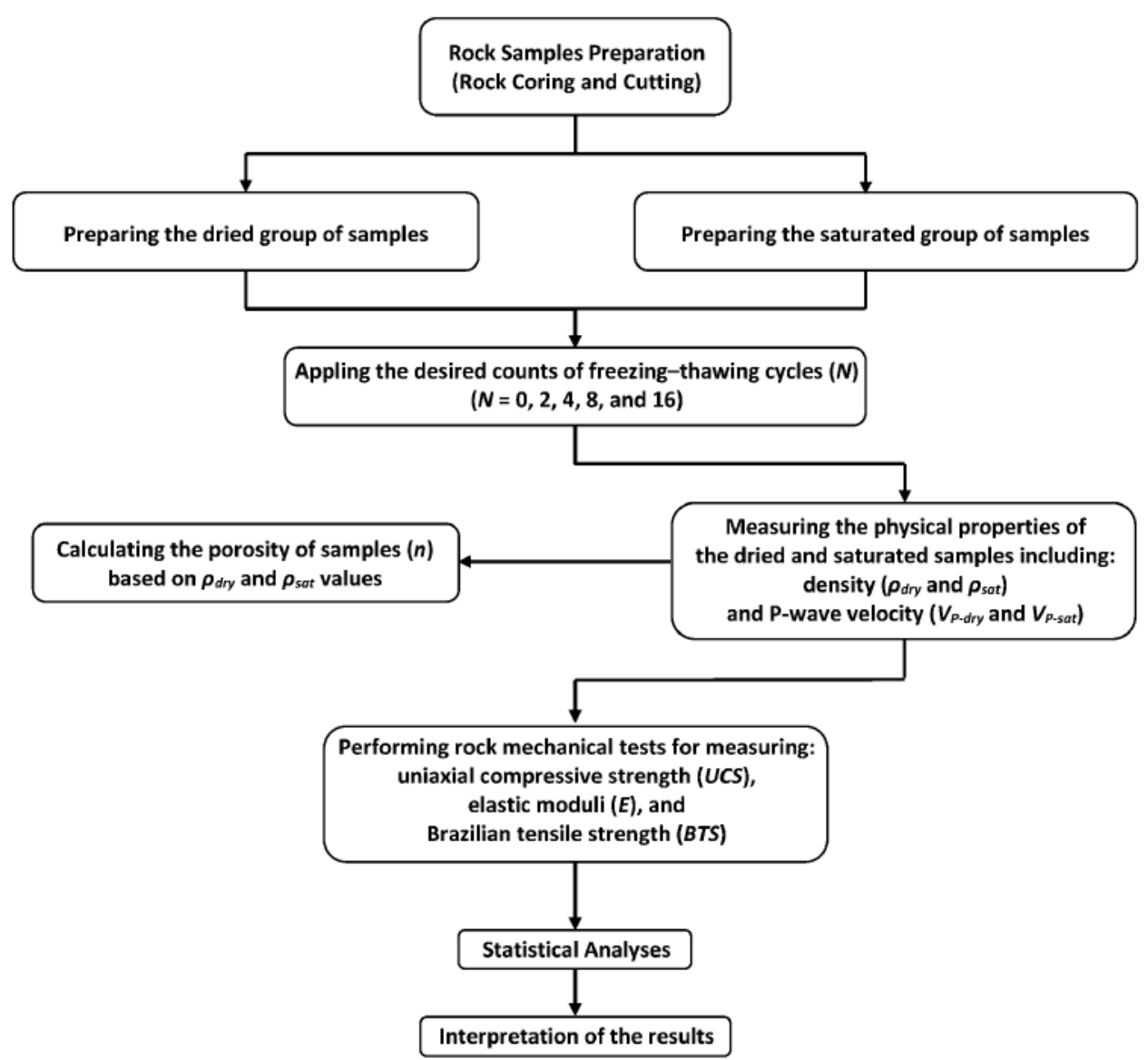

Figure 5: The steps of performed experimental study.

groups and the maximum counts reached 16 cycles (32 days) for the last group of samples. The flowchart of Figure 5 shows the performed steps during this experimental study.

The testing program includes the measurement of density $(\rho)$, P-wave velocity $\left(V_{p}\right)$, uniaxial compressive strength (UCS), modulus of elasticity $(E)$, and Brazilian tensile strength (BTS) in both dry and saturated conditions. At the first step, the non-destructive tests for measuring $\rho$ and $V_{p}$ values were performed on all core samples. Density was calculated as the ratio of sample mass, measured with a balance, to sample volume [60]. The dimensions of the core sample were measured with a caliper and used to calculate the volume. Weight volume relationships were used to calculate the porosity $(n)$ of testing samples from $\rho_{d r y}$ and $\rho_{\text {sat }}$ values. Moreover, an ultrasonic testing device was used to measure $V_{p}$ values [61] (Figure 6). In addition to non-destructive tests, the testing program included five uniaxial compressive tests and five Brazilian tensile tests per group of rock samples. An automatic hydraulic compression press was used to perform UCS and BTS tests (Figure 7a). Modulus of elasticity was measured simultaneously with the UCS tests. To do this, a load cell and a displacement sensor were used along with a data logger (Figure $\mathbf{7 b}$ ) to plot stress-strain curves. Figure $\mathbf{8}$ shows a set of stress-strain curves plotted for dry sandstone samples, which had experienced four freezing-thawing cycles. Finally, an ISRM recommended testing frame was used to measure BTS values (Figure 7c). Figure 9 shows the photos of some saturated rock samples, experienced different counts of freezing-thawing cycles, after UCS tests.

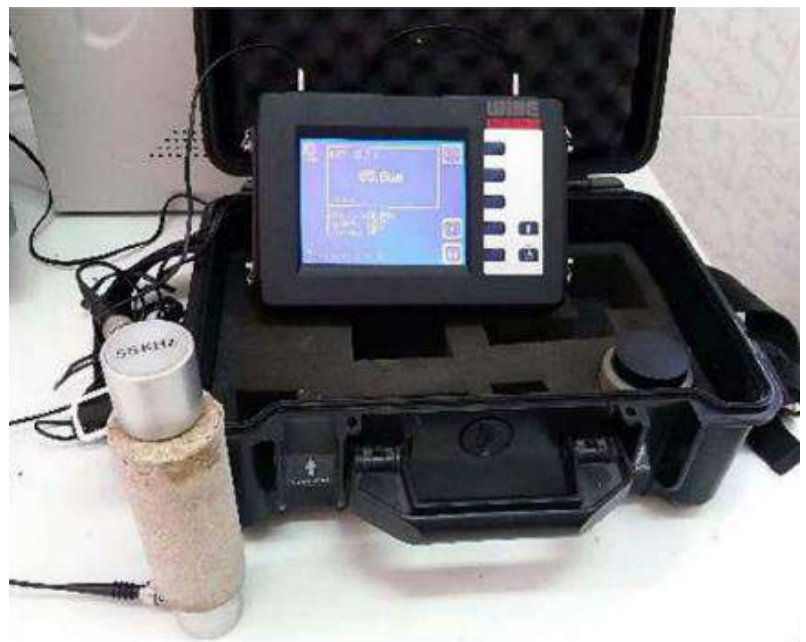

Figure 6: The ultrasonic testing device used to measure $V_{P}$ values

\section{RESULTS AND DISCUSSION}

All of the mentioned tests were performed based on the recommended standards from ISRM [59]. For each 


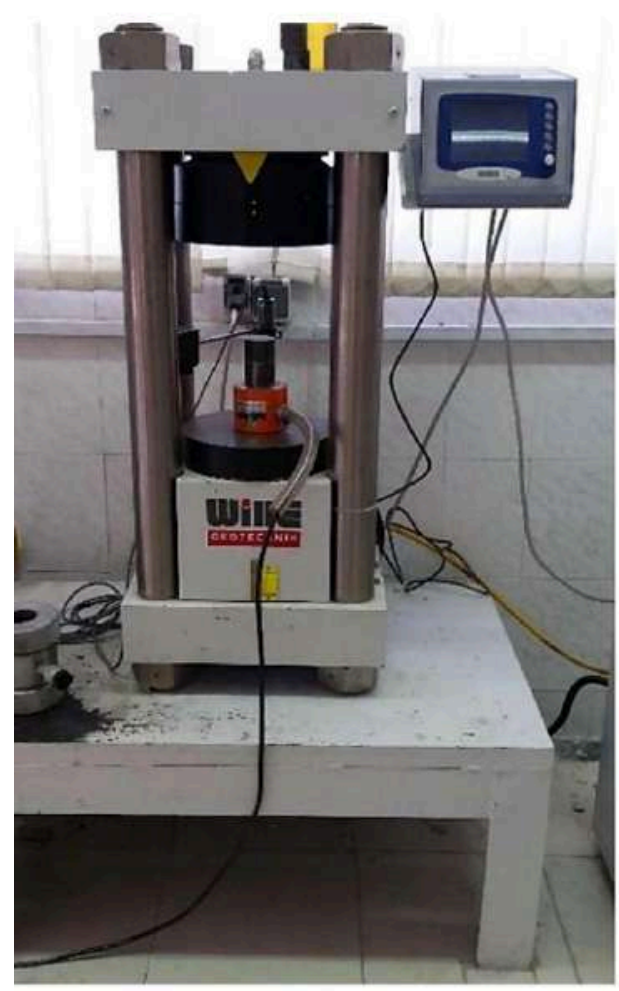

(a)

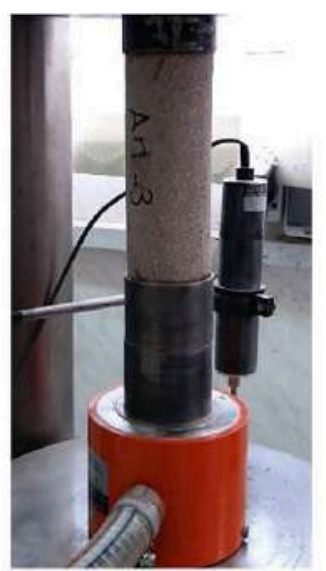

(b)

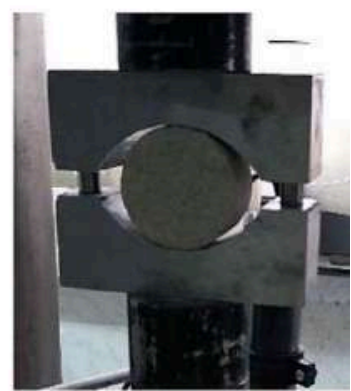

(c)

Figure 7: a) compressive testing machine used to perform UCS and BTS tests, b) measuring sample load and displacement in a UCS test, c) BTS loading frame.

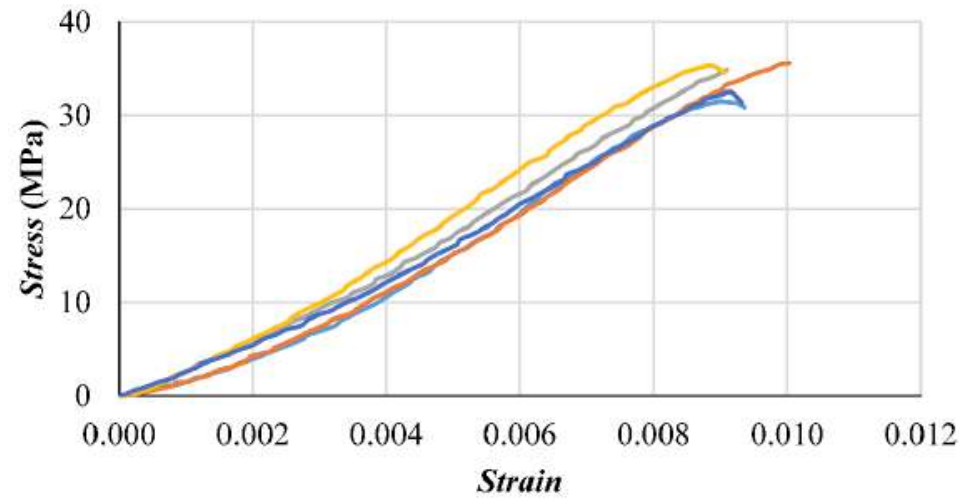

$\longrightarrow$ Sd-11 $\longrightarrow$ Sd-12 Sd-13 Sd-14 $\longrightarrow$ Sd-15

Figure 8: Stress - strain curves plotted for sandstone samples after experiencing four freezing-thawing cycles.

freezing-thawing cycle count of $0,2,4,8$, and 16 , five rock cores were tested and the relevant average amounts were calculated for $V_{p}, U C S$, and $E$, values under both dry and saturated conditions. Similarly, five disk samples were tested to calculate the average value of $B T S_{d r y}$ and $B T S_{\text {sat }}$.

Figures 10 to 16 show the variations of measured physical and mechanical properties against the counts of weathering cycles. The graphs of $a, b, c, d$, and e in these Figures exhibit the plots of porosity $(n), \mathrm{P}$-wave velocity $\left(V_{P}\right)$, uniaxial compressive strength (UCS), elastic modulus $(E)$, and Brazilian tensile strength (BTS) changes respectively. Both the variations of dry and saturated parameters are included in the plots. Although the range of measured values in different rock types are different, however, the obtained trends are the same.

The plots of (a) in Figures 10 to 16 reveal the variations of porosity during thermal cycles. The general trend is increasing the porosity values in the first few cycles of freezing-thawing followed by nearly horizontal fitted trends at the end parts of graphs. The obtained trends in andesite- 2 and granite samples (Figures 11a and 13a respectively) are different somewhat. These samples have low initial porosity values $(2.47 \%$ and $0.52 \%$ for andesite- 2 and granite 


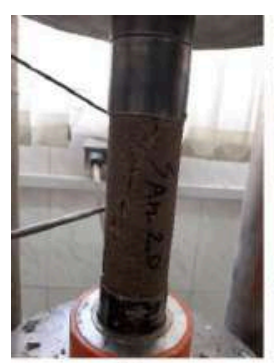

(a)

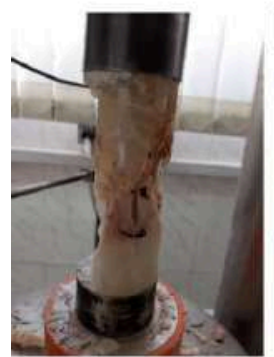

(e)

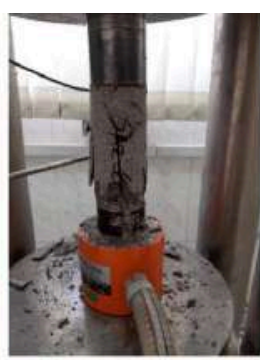

(b)

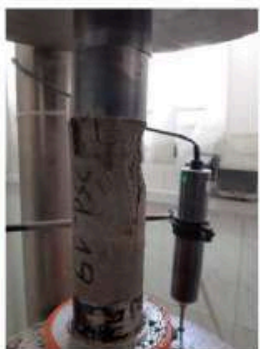

(f)

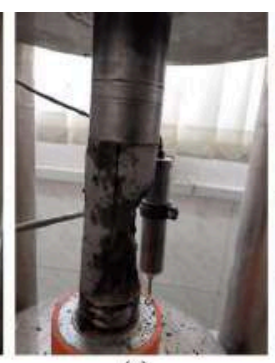

(c)

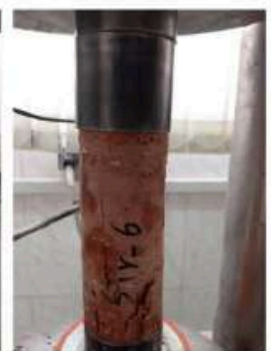

(g)

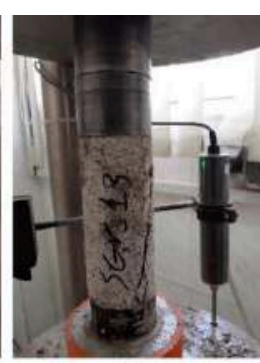

(d)

Figure 9: Photos of some saturated rock samples, experienced different counts of freezing-thawing cycles, after UCS tests: a) andesite-1, b) andesite-2, c) basalt, d) granite, e) onyx, f) sandstone, and g) travertine.

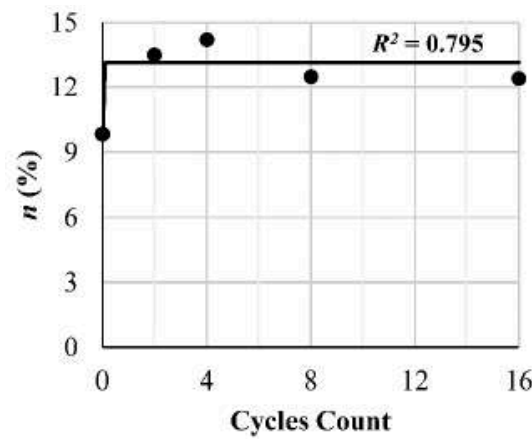

(a)

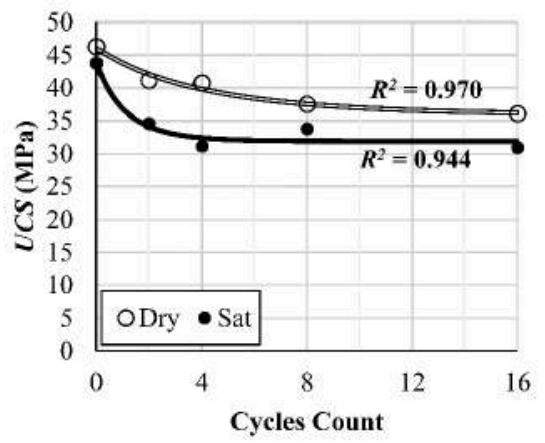

(c)

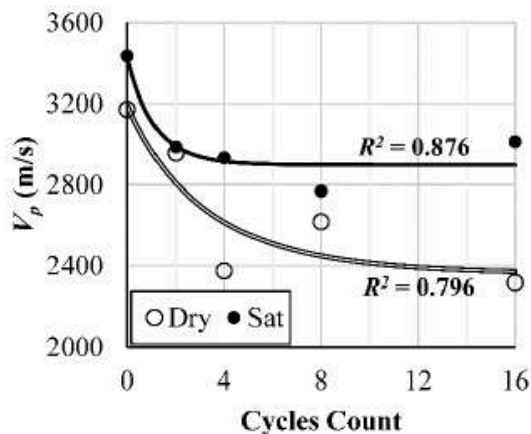

(b)

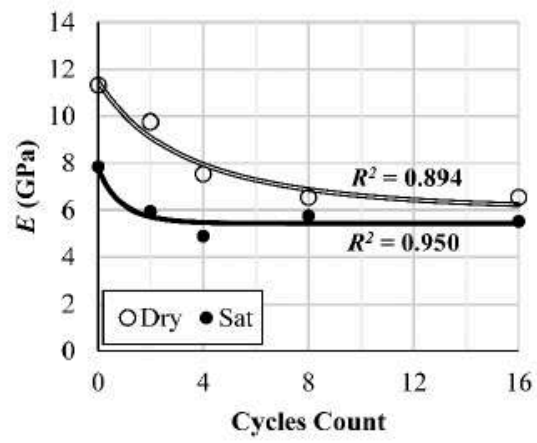

(d)

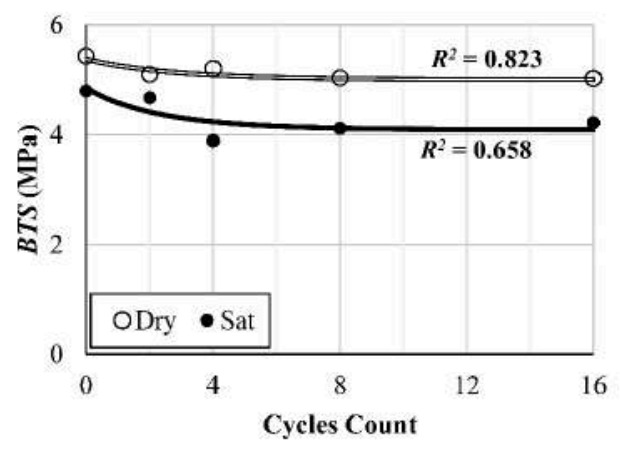

(e)

Figure 10: the variation of a) porosity $(n)$, b) P-wave velocity $\left(V_{P}\right)$, c) uniaxial compressive strength $(U C S)$, d) elastic modulus $(E)$, and e) Brazilian tensile strength (BTS) values against freezing-thawing cycles in andesite-1 samples. 


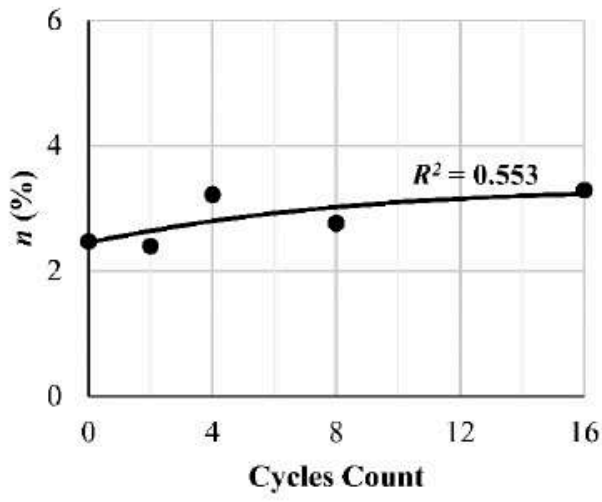

(a)

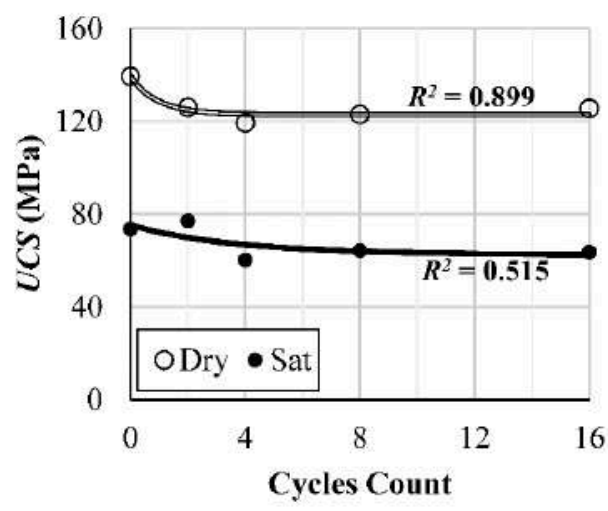

(c)

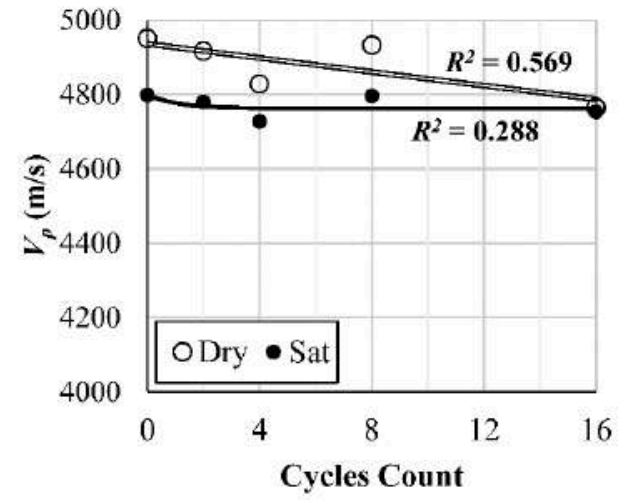

(b)

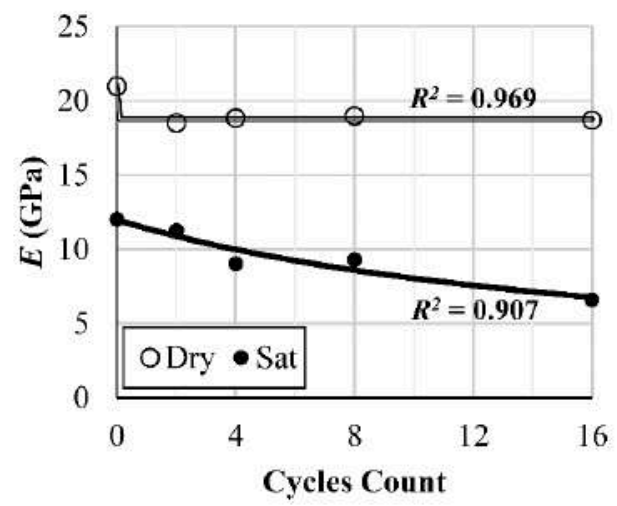

(d)

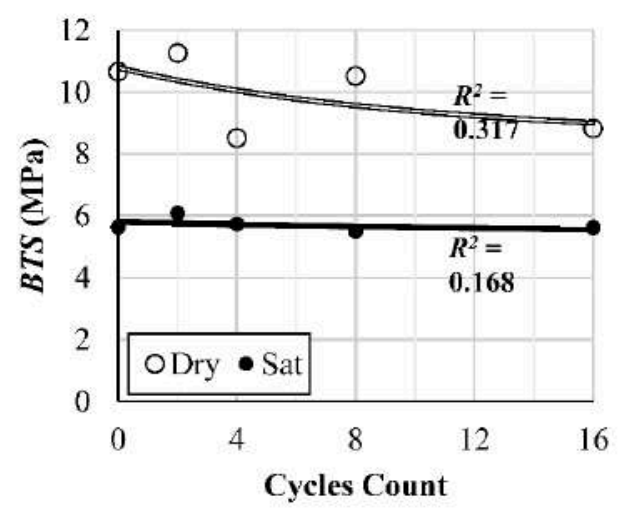

(e)

Figure 11: the variation of a) porosity $(n)$, b) P-wave velocity $\left(V_{P}\right)$, c) uniaxial compressive strength (UCS), d) elastic modulus $(E)$, and e) Brazilian tensile strength (BTS) values against freezing-thawing cycles in andesite-2 samples

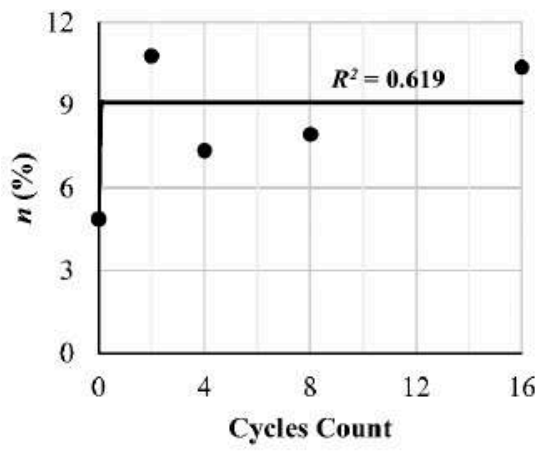

(a)

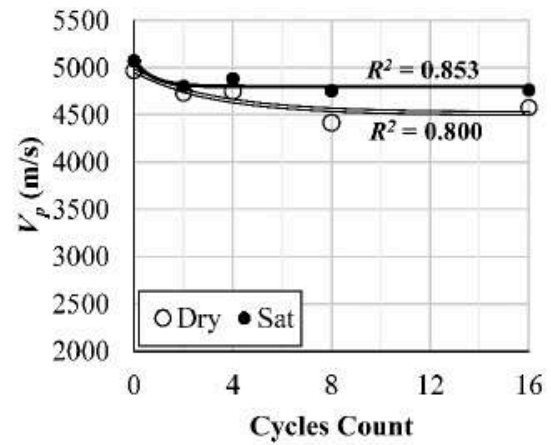

(b) 
(Figure 12). Continued.

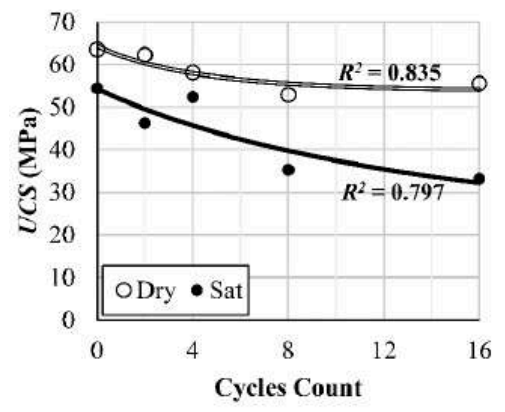

(c)

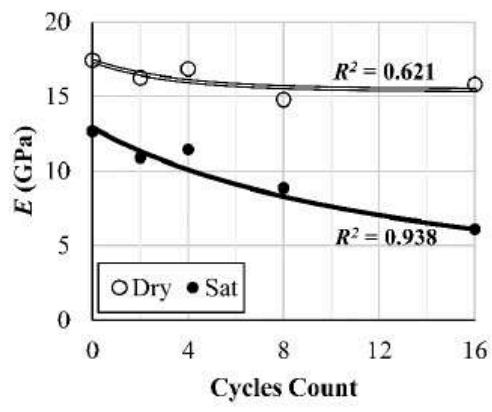

(d)

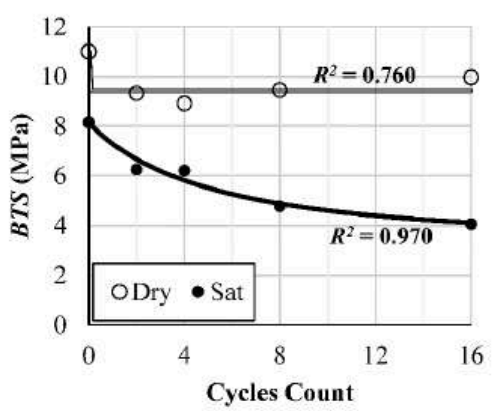

(e)

Figure 12: the variation of a) porosity $(n), \mathbf{b})$ P-wave velocity $\left(V_{P}\right)$, c) uniaxial compressive strength (UCS), d) elastic modulus $(E)$, and $\mathbf{e})$ Brazilian tensile strength $(B T S)$ values against freezing-thawing cycles in basalt samples.

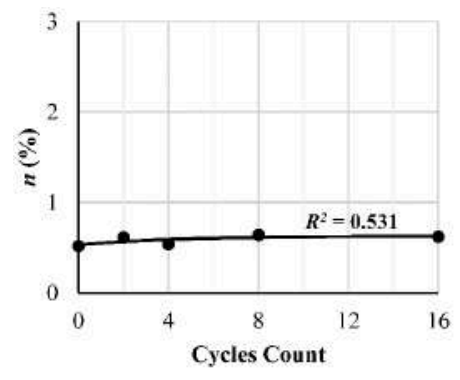

(a)

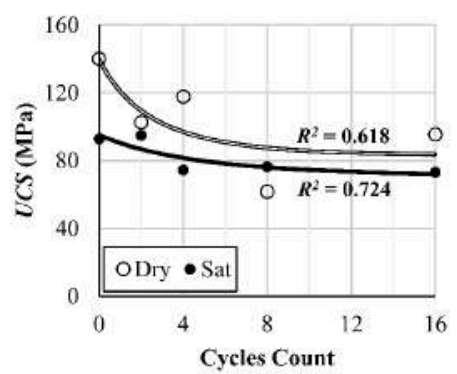

(c)

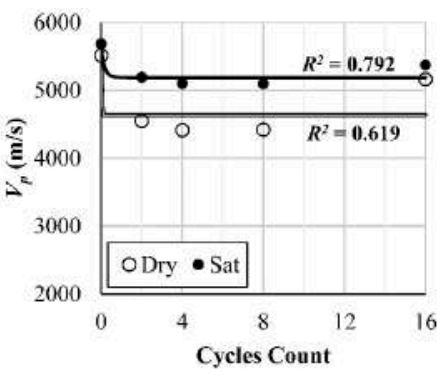

(b)

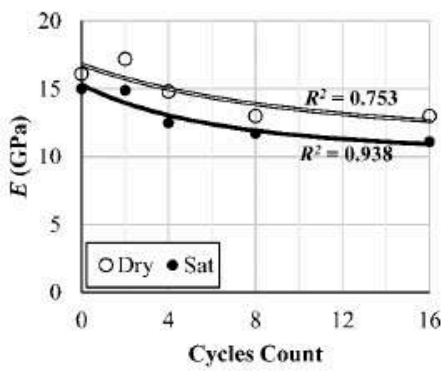

(d)

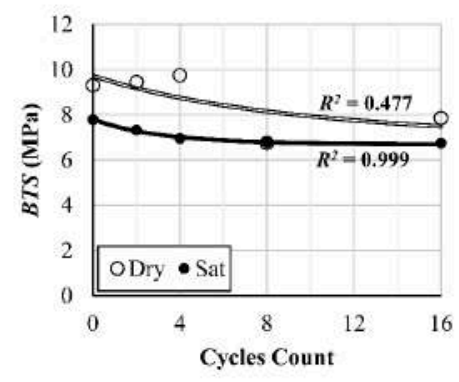

(e)

Figure 13: the variation of a) porosity $(n)$, b) P-wave velocity $\left(V_{P}\right)$, c) uniaxial compressive strength $(U C S)$, d) elastic modulus $(E)$, and $\mathbf{e})$ Brazilian tensile strength $(B T S)$ values against freezing-thawing cycles in granite samples. 


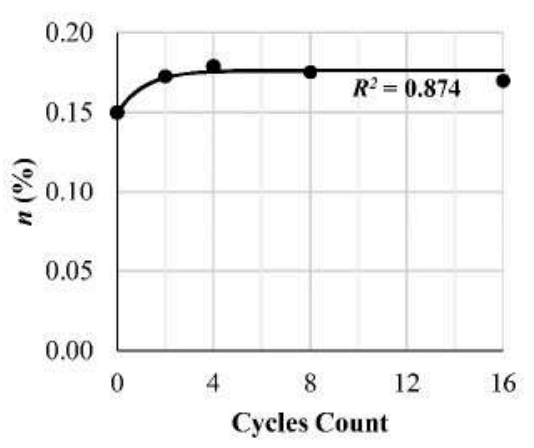

(a)

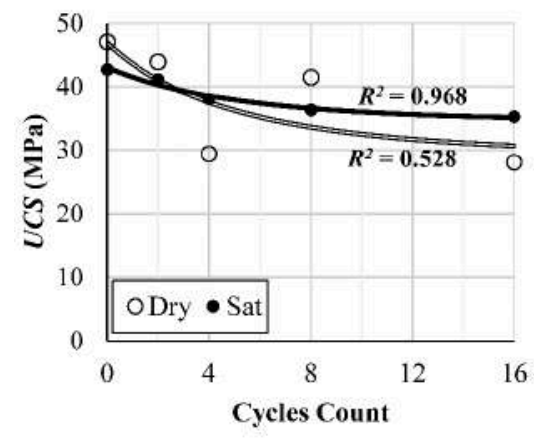

(c)

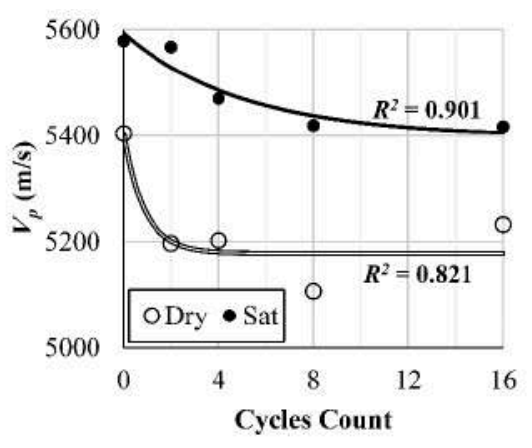

(b)

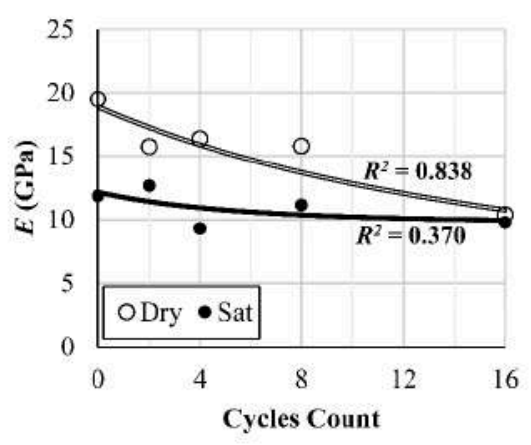

(d)

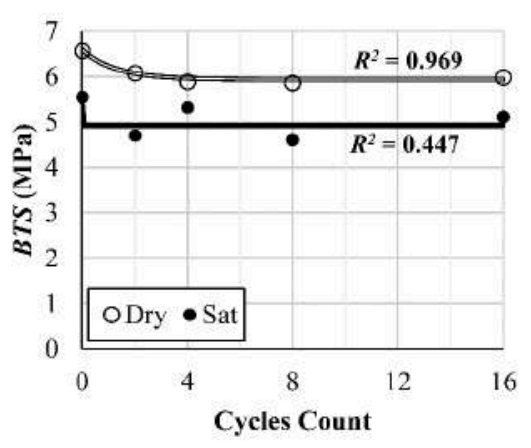

(e)

Figure 14: the variation of a) porosity $(n)$, b) P-wave velocity $\left(V_{P}\right)$, c) uniaxial compressive strength (UCS), d) elastic modulus $(E)$, and $\mathbf{e})$ Brazilian tensile strength $(B T S)$ values against freezing-thawing cycles in onyx samples.

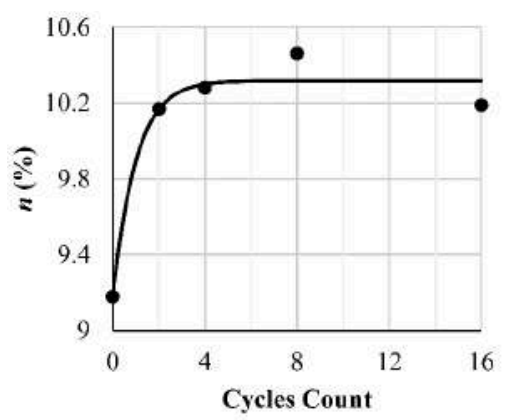

(a)

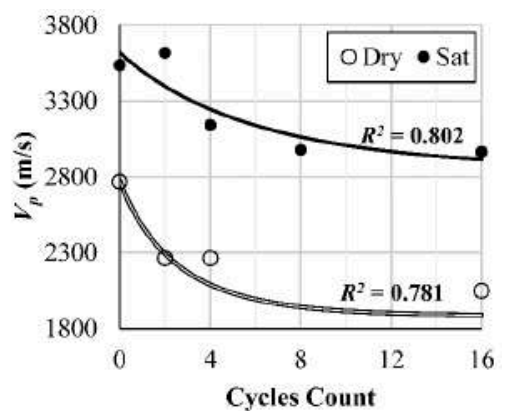

(b) 
(Figure 15). Continued.

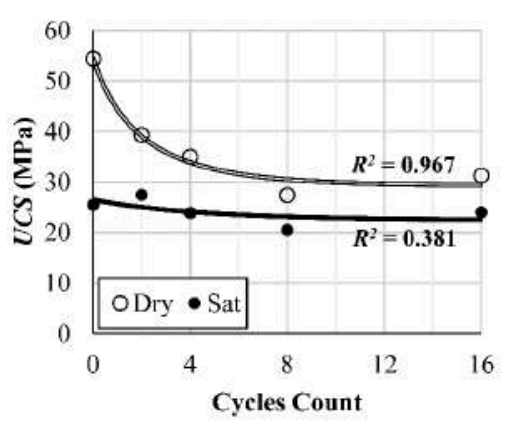

(c)

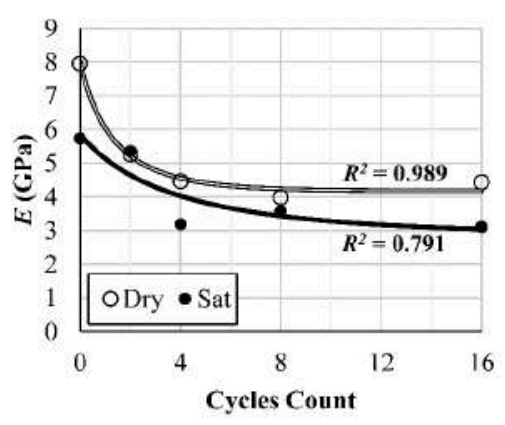

(d)

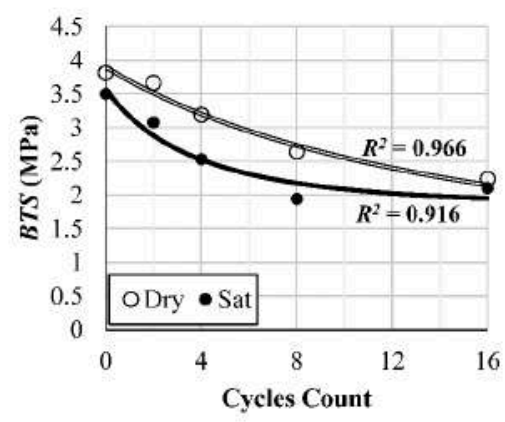

(e)

Figure 15: the variation of a) porosity $(n)$, b) P-wave velocity $\left(V_{P}\right)$, c) uniaxial compressive strength $(U C S)$, d) elastic modulus $(E)$, and $\mathbf{e})$ Brazilian tensile strength $(B T S)$ values against freezing-thawing cycles in sandstone samples.

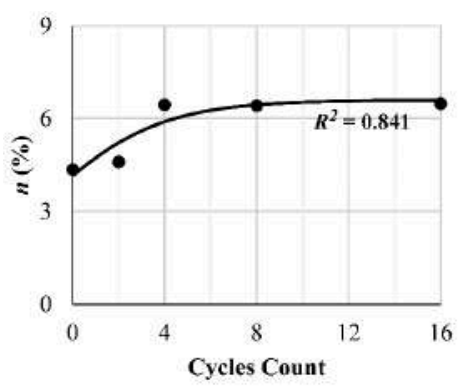

(a)

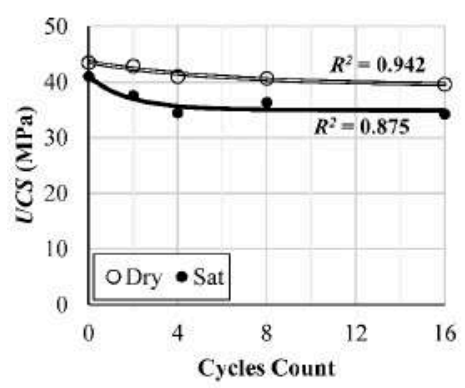

(c)

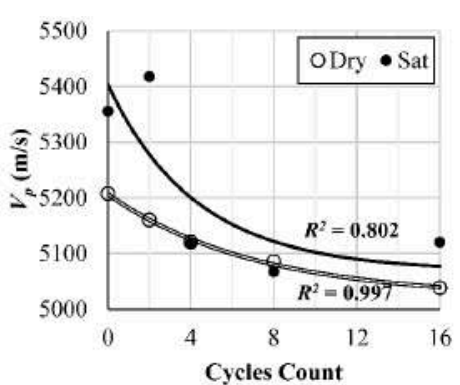

(b)

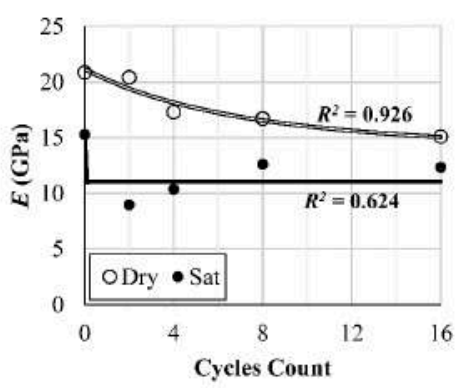

(d)

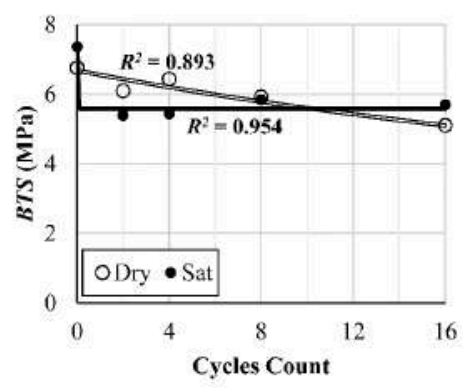

(e)

Figure 16: the variation of a) porosity $(n)$, b) P-wave velocity $\left(V_{P}\right)$, c) uniaxial compressive strength (UCS), d) elastic modulus $(E)$, and $\mathbf{e})$ Brazilian tensile strength $(B T S)$ values against freezing-thawing cycles in travertine samples. 
respectively) and high initial dry UCS values (139.4MPa and 140.0 MPa for andesite-2 and granite respectively). These samples exhibit a low range of porosity changes along with a low rate of variation. However, the rest of the tested samples (andesite-1, basalt, onyx, sandstone, and travertine), which have lower UCS and higher porosity values, show a greater range of changes with a high rate of variations in the few initial cycles of weathering. Increasing the count of heat-cool cycles, $n$ converges to a constant value in all graphs. Therefore, the general trend is increasing porosity values during initial cycles and converging to a constant value at the end cycles. However, it seems that the strong samples exhibit a low range of porosity changes accompanied by a low rate of variations.

The plots of (b) in Figures 10 to 16 show the changes of $P$-wave velocity values versus freezingthawing cycle counts. Except for andesite-2 sample (Figures $4 c$ and $9 b$ ), the $V_{\text {sat }}$ values are greater than the $V_{\text {dry }}$ ones in all plots. This is due to the effect of the filling pore spaces by water in saturated rock samples in which facilitates the transmission of $\mathrm{P}$-wave and increases the measured velocity values. It seems that the contradictory trends of the andesite- 2 sample are due to the measuring errors, especially considering the relatively close values recorded under dry and saturated conditions. Increasing the count of freezingthawing cycles decrease the recorded P-wave velocity values. The trend is the same in all tested samples as well as dry and saturated conditions. The rate of variations is high during the cycles of zero to four and passing cycle 8 the range of $V_{P}$ variations becomes small and the fitted trends are sub-horizontal.

The plots of (b), (c), and (e) in Figures 10 to 16 show the variations of uniaxial compressive strength, elastic modulus, and Brazilian tensile strength respectively against weathering cycles in the different rock types. In all tested samples and for the all investigated cycles, the recorded mechanical parameters in the dry condition are greater than those of the saturated one. However, the fitted trends are the same as the trends of $V_{P}$. Increasing the experienced freezing-thawing cycle counts decreases the measured mechanical parameters. The rate of degradation is high during the initial cycles. However, progressing the weathering cycles, the rate of variations decreases, and the fitted trends become sub-horizontal.

To describe the obtained trends for different properties on various rock types, statistical analyses were performed on the recorded data. The results showed that a logistic function with the following general form can describe the trend of the changes of different properties versus freezing-thawing cycle counts:

$f(x)=\frac{a}{1+b e^{c x}}$

Where $f(x)$ is the value of the different parameters of $n(\%), V_{P}(\mathrm{~m} / \mathrm{s})$, UCS (MPa), E (GPa), and BTS (MPa), $x$ is the count of freezing-thawing cycles and $a, b$, and $c$ are constants. Using nonlinear regression analyses, the constant values were determined for the different properties of various rock types. Table 1 summarizes the obtained constant values for different rock types in both dry and saturated conditions. Correlation coefficient values of the fitted trends are reported in the table as well as the plots of Figures 10 to 16 . The obtained correlation coefficient values are significant in most cases. This means that the proposed function can predict the variations of all mentioned properties during weathering cycles with a high degree of precision.

Figure 17 shows the variations of porosity values after a given number of weathering cycles $\left(n_{i}, i=2,3,4\right.$, and 8 ) versus initial porosity values $\left(n_{0}\right)$ for the different tested rock samples. A power function with the following general form is fitted to the data points:

$n_{i}=a_{i} n_{0} b_{i} \quad(\mathrm{i}=2,4,8$, and 16$)$

Where $n_{i}$ is the porosity after the $i$-th freezingthawing cycle $(\%), n_{0}$ is the initial porosity of rock sample before heat-cool cycles (\%) and $a_{i}$ and $b_{i}$ are constant values for each cycle counts. The constant values and relevant correlation coefficient are summarized in Table 2. Equation (2) calculates porosity values at the end of different weathering cycles from the relevant initial porosity values. As it can be seen from Figure 17, the obtained correlation coefficients are excellent. In the graphs of Figure 17, the 1:1 lines are plotted as dashed lines. Lying all data points and relevant fitted trends above these lines mean that $n_{i}$ (porosity values after $i$-th freeze-thaw cycles) values are greater than $n_{0}$ (initial porosity values before freezing-thawing) ones. Comparing the fitted trends to $1: 1$ lines reveals that when the initial porosity values are small, the fitted trends are closer to the $1: 1$ lines. In other words, the effect of freezingthawing cycles on the porosity of low porous rock types is small, and the higher the initial porosity of the tested sample, the more the distance between the fitted and $1: 1$ lines and therefore the greater the effect of weathering on the sample porosity.

Figures 18 and 19 show the variations of P-wave velocity values after experiencing different weathering cycle counts respectively for dry and saturated rock samples. The $1: 1$ line is plotted on the graphs as well. 
Table 1: The Relevant Constant Values and Correlation Coefficient of Proposed Function for Predicting the Different Mechanical Properties of Various Rock Types during Freezing-Thawing Cycles

\begin{tabular}{|c|c|c|c|c|c|c|c|c|c|c|}
\hline \multirow{2}{*}{ Rock Type } & \multirow{2}{*}{$\begin{array}{l}\text { Const. } \\
\text { Values }\end{array}$} & \multirow{2}{*}{$n$} & \multicolumn{2}{|c|}{$V_{P}$} & \multicolumn{2}{|c|}{ UCS } & \multicolumn{2}{|c|}{$E$} & \multicolumn{2}{|c|}{ BTS } \\
\hline & & & Dry & Sat. & Dry & Sat. & Dry & Sat. & Dry & Sat. \\
\hline \multirow{4}{*}{ andesite-1 } & $a$ & 13.145 & 2359.557 & 2897.812 & 35.915 & 31.927 & 6.014 & 5.440 & 5.006 & 4.084 \\
\hline & $b$ & 0.336 & -0.261 & -0.156 & -0.220 & -0.272 & -0.476 & -0.303 & -0.070 & -0.159 \\
\hline & $c$ & 45.432 & 0.245 & 0.810 & 0.203 & 0.713 & 0.168 & 0.898 & 0.346 & 0.379 \\
\hline & $R^{2}$ & 0.795 & 0.796 & 0.876 & 0.970 & 0.944 & 0.950 & 0.894 & 0.823 & 0.658 \\
\hline \multirow{4}{*}{ andesite-2 } & $a$ & 3.314 & 60.160 & 4762.432 & 122.866 & 62.290 & 18.750 & 1.368 & 8.404 & 5.276 \\
\hline & $b$ & 0.353 & -0.988 & -0.008 & -0.119 & -0.173 & -0.107 & -0.886 & -0.221 & -0.090 \\
\hline & $c$ & 0.160 & 0.000 & 0.890 & 0.982 & 0.233 & 36.592 & 0.007 & 0.075 & 0.037 \\
\hline & $R^{2}$ & 0.553 & 0.569 & 0.288 & 0.899 & 0.515 & 0.969 & 0.907 & 0.317 & 0.168 \\
\hline \multirow{4}{*}{ basalt } & $a$ & 9.113 & 4508.314 & 4796.234 & 53.785 & 13.511 & 15.420 & 0.001 & 9.425 & 3.629 \\
\hline & $b$ & 0.871 & -0.093 & -0.055 & -0.164 & -0.751 & -0.113 & -1.000 & -0.143 & -0.553 \\
\hline & $c$ & 105.690 & 0.280 & 1.246 & 0.207 & 0.016 & 0.269 & 0.000 & 51.717 & 0.096 \\
\hline & $R^{2}$ & 0.619 & 0.800 & 0.853 & 0.835 & 0.797 & 0.621 & 0.938 & 0.760 & 0.970 \\
\hline \multirow{4}{*}{ granite } & $a$ & 0.628 & 4637.000 & 5191.000 & 83.175 & 70.978 & 11.397 & 10.359 & 6.824 & 6.689 \\
\hline & $b$ & 0.183 & -0.159 & -0.087 & -0.405 & -0.254 & -0.321 & -0.324 & -0.298 & -0.143 \\
\hline & $c$ & 0.272 & 64.286 & 6.190 & 0.261 & 0.168 & 0.073 & 0.113 & 0.076 & 0.278 \\
\hline & $R^{2}$ & 0.531 & 0.619 & 0.792 & 0.618 & 0.724 & 0.753 & 0.898 & 0.477 & 0.999 \\
\hline \multirow{4}{*}{ onyx } & $a$ & 0.176 & 5178.200 & 5396.875 & 29.396 & 34.594 & 0.002 & 9.816 & 5.931 & 4.925 \\
\hline & $b$ & 0.178 & -0.042 & -0.035 & -0.373 & -0.196 & -1.000 & -0.193 & -0.102 & -0.105 \\
\hline & $c$ & 0.909 & 1.124 & 0.193 & 0.136 & 0.162 & 0.000 & 0.157 & 0.741 & 117.103 \\
\hline & $R^{2}$ & 0.874 & 0.821 & 0.901 & 0.528 & 0.968 & 0.838 & 0.370 & 0.969 & 0.447 \\
\hline \multirow{4}{*}{ sandstone } & $a$ & 10.317 & 1884.003 & 2845.199 & 29.303 & 22.424 & 4.176 & 2.896 & 0.632 & 1.866 \\
\hline & $b$ & 0.124 & -0.321 & -0.214 & -0.462 & -0.155 & -0.479 & -0.505 & -0.838 & -0.477 \\
\hline & $c$ & 1.060 & 0.295 & 0.138 & 0.306 & 0.198 & 0.436 & 0.147 & 0.011 & 0.151 \\
\hline & $R^{2}$ & 0.963 & 0.781 & 0.802 & 0.967 & 0.381 & 0.989 & 0.791 & 0.966 & 0.916 \\
\hline \multirow{4}{*}{ travertine } & $a$ & 6.603 & 5020.016 & 5068.279 & 39.273 & 34.913 & 13.993 & 11.075 & 0.002 & 5.575 \\
\hline & $b$ & 0.593 & -0.036 & -0.062 & -0.100 & -0.150 & -0.340 & -0.276 & -1.000 & -0.247 \\
\hline & $c$ & 0.400 & 0.138 & 0.223 & 0.150 & 0.486 & 0.098 & 182.631 & 0.000 & 37.759 \\
\hline & $R^{2}$ & 0.841 & 0.997 & 0.672 & 0.942 & 0.875 & 0.926 & 0.624 & 0.893 & 0.954 \\
\hline
\end{tabular}

Table 2: The Relevant Constant Values and Correlation Coefficients for Equations Predicting the Measured Properties Based on Initial Values in Different Weathering Cycles

\begin{tabular}{|c|c|c|c|c|c|c|}
\hline Property & $\begin{array}{l}\text { moisture } \\
\text { condition }\end{array}$ & $\begin{array}{l}\text { Cycle Counts } \\
(i, j, k, l, \text { and } m)\end{array}$ & 2 & 4 & 8 & 16 \\
\hline \multirow{3}{*}{$\begin{array}{l}\text { Porosity }(n) \\
n_{i}=a_{i} n_{0} b_{i}\end{array}$} & \multirow{3}{*}{ - } & $a_{i}$ & 1.2063 & 1.2350 & 1.2511 & 1.2933 \\
\hline & & $b_{i}$ & 1.0394 & 1.0483 & 1.0265 & 1.0472 \\
\hline & & $R^{2}$ & 0.9736 & 0.9941 & 0.9930 & 0.9833 \\
\hline \multirow{6}{*}{$\begin{array}{l}\text { P-Wave Velocity }\left(V_{P}\right) \\
V_{P-j}=a_{j} V_{P-0}+b_{j}\end{array}$} & \multirow{3}{*}{ dry } & $a_{j}$ & 1.0931 & 1.073 & 1.2877 & 1.2476 \\
\hline & & $b_{j}$ & -512.82 & -411.87 & -1559.7 & -1332.3 \\
\hline & & $R^{2}$ & 0.9794 & 0.8053 & 0.9680 & 0.9594 \\
\hline & \multirow{3}{*}{ saturated } & $a_{j}$ & 1.0002 & 1.0683 & 1.1282 & 1.1232 \\
\hline & & $b_{j}$ & -157.59 & -624.09 & -981.15 & -882.72 \\
\hline & & $R^{2}$ & 0.9363 & 0.9659 & 0.9606 & 0.9854 \\
\hline
\end{tabular}


(Table 2). Continued.

\begin{tabular}{|c|c|c|c|c|c|c|}
\hline Property & $\begin{array}{l}\text { moisture } \\
\text { condition }\end{array}$ & $\begin{array}{c}\text { Cycle Counts } \\
(i, j, k, l, \text { and } m)\end{array}$ & 2 & 4 & 8 & 16 \\
\hline \multirow{6}{*}{$\begin{array}{l}\text { Uniaxial Compressive Strength (UCS) } \\
U C S_{k}=a_{k} U C S_{0}+b_{k}\end{array}$} & \multirow{3}{*}{ dry } & $a_{k}$ & 0.7728 & 0.8758 & 0.5852 & 0.8161 \\
\hline & & $b_{k}$ & 6.485 & -3.7581 & 10.301 & -3.459 \\
\hline & & $R^{2}$ & 0.9420 & 0.9731 & 0.6444 & 0.9140 \\
\hline & \multirow{3}{*}{ saturated } & $a_{k}$ & 1.0778 & 0.7747 & 0.8417 & 0.7839 \\
\hline & & $b_{k}$ & -6.2565 & 3.5694 & -1.665 & 0.1988 \\
\hline & & $R^{2}$ & 0.9636 & 0.9546 & 0.9515 & 0.9228 \\
\hline \multirow{6}{*}{$\begin{array}{l}\text { Elastic Modulus }(E) \\
E_{l}=a_{l} E_{0}+b_{l}\end{array}$} & \multirow{3}{*}{ dry } & $a_{l}$ & 1.0227 & 1.0786 & 1.0994 & 0.9083 \\
\hline & & $b_{l}$ & -1.9375 & -3.849 & -5.0979 & -2.8136 \\
\hline & & $R^{2}$ & 0.9108 & 0.9535 & 0.9779 & 0.7674 \\
\hline & \multirow{3}{*}{ saturated } & $a_{l}$ & 0.7661 & 0.9195 & 0.8931 & 0.8288 \\
\hline & & $b_{l}$ & 1.1973 & -1.8832 & -1.2647 & -1.7242 \\
\hline & & $R^{2}$ & 0.6055 & 0.9044 & 0.9206 & 0.7703 \\
\hline \multirow{6}{*}{$\begin{array}{l}\text { Brazilian Tensile Strength (BTS) } \\
B T S_{m}=a_{m} B T S_{0}+b_{m}\end{array}$} & \multirow{3}{*}{ dry } & $a_{m}$ & 0.9748 & 0.8034 & 0.9344 & 0.947 \\
\hline & & $b_{m}$ & -0.1735 & 0.6989 & -0.5501 & -0.8159 \\
\hline & & $R^{2}$ & 0.9330 & 0.8810 & 0.9127 & 0.9592 \\
\hline & \multirow{3}{*}{ saturated } & $a_{m}$ & 0.6814 & 0.7745 & 0.7188 & 0.5722 \\
\hline & & $b_{m}$ & 1.2002 & 0.4251 & 0.4031 & 1.2988 \\
\hline & & $R^{2}$ & 0.7272 & 0.7989 & 0.6460 & 0.4287 \\
\hline
\end{tabular}

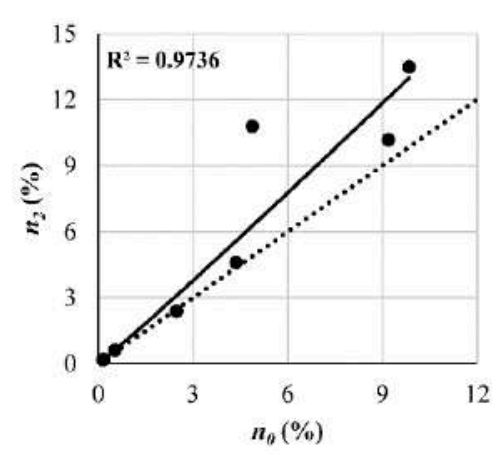

(a)

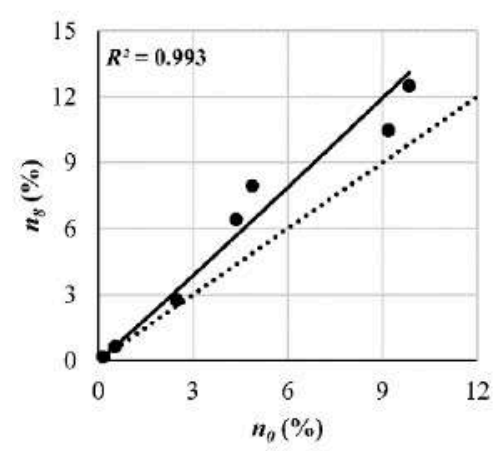

(c)

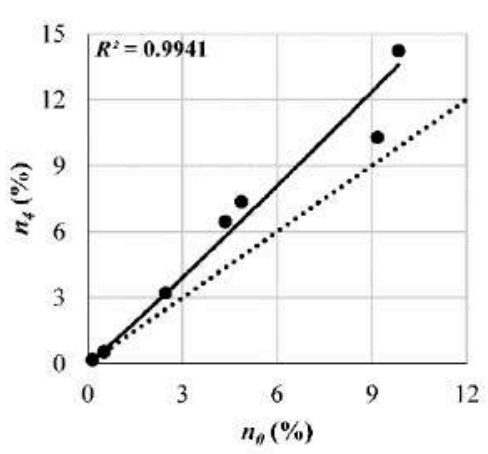

(b)

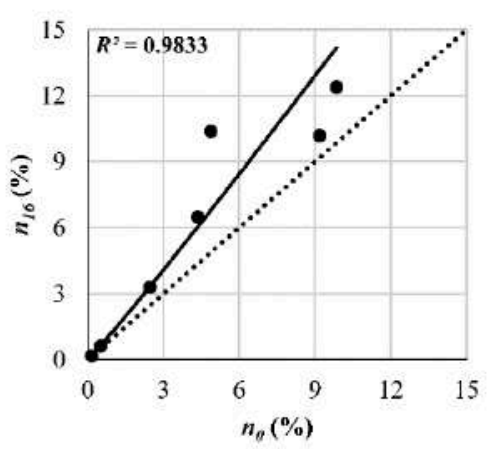

(d)

Figure 17: The variations of porosity values versus initial porosity values $\left(n_{0}\right)$ for the different tested rock samples after a) two, b) four, c) eight, and d) sixteen freeze-thaw cycles.

A linear equation with the following general form is fitted on the data points of Figures 18 and 19:

$V_{P-j}=a_{i} V_{P-0}+b_{i} \quad(\mathrm{j}=2,4,8$, and 16$)$
Where $V_{p-j}$ is the $\mathrm{P}$-wave velocity after the $j$-th freeze-thaw cycle $(\mathrm{m} / \mathrm{s}), \quad V_{p-0}$ is the initial P-wave velocity before experiencing weathering cycles $(\mathrm{m} / \mathrm{s})$, and $a_{j}$ and $b_{j}$ are constant values. The relevant $a_{j}$ and $b_{j}$ 
values along with the obtained correlation coefficients are summarized in Table 2. In the plots of Figures 18 and 19, the data point and fitted trend lines lie below 1:1 lines meaning that experiencing freeze-thaw cycles decreases $V_{P-j}$ values comparing to $V_{P-0}$ ones. In dry rock samples (Figure 18), the fitted trend lines cross 1:1 lines in the high $V_{P_{-j}}$ ranges, and the distance between the fitted trends and 1:1 lines increases with the decrease of $V_{P_{-j}}$ values. This means that in dry rock samples, the effect of weathering in the reduction of recorded $V_{P-j}$ values increases as the initial $P$-wave velocity values decrease. Based on Figure 18, it seems that when $V_{P-0}$ is greater than $5000 \mathrm{~m} / \mathrm{s}$, freeze-thaw cycles nearly do not affect the $V_{P}$ values. In Figures $18 \mathrm{c}$ and $\mathbf{d}$, in the low range of $V_{P}$ values, the distance of fitted trend lines to $1: 1$ ones is greater than those of Figures $18 \mathbf{a}$ and $\mathbf{b}$. This is the consequence of the effect of progressing weathering cycles on the measured $\mathrm{P}$-wave velocities. As it can be seen, the effect in cycles eight and sixteen is greater than the effect in two and four ones. The obtained trends in the plots of Figure 19 (saturated samples) are somewhat different. The fitted trend lines do not cross 1:1 lines in the range of obtained data points. In the plots of 19a and $19 \mathrm{~b}$, the fitted trend lines are more or less parallel to the $1: 1$ lines. However, in the Figures of $19 c$ and $19 d$, the distance between fitted and 1:1 lines increases in the low range of $V_{P_{-j}}$ values. It seems that in the first two weathering phases, the effect of freeze-thaw cycles on the reduction of the recorded $\mathrm{P}$-wave velocities is more or less the same for the whole range of $V_{P-O}$. However, progressing the weathering cycles

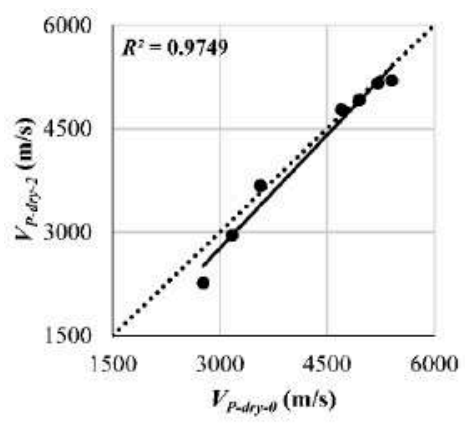

(a)

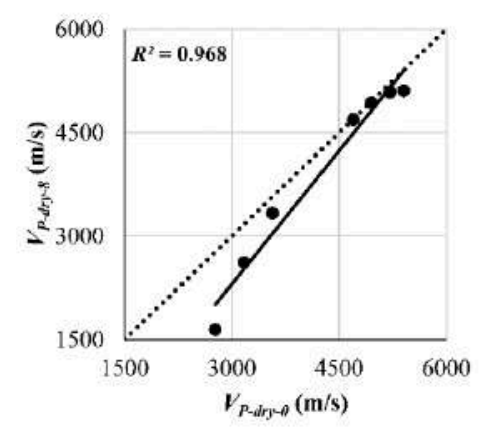

(c) increases the effect on the samples, which have low $V_{P-0}$ values. The lack of intersection between fitted trends and 1:1 lines in saturated samples means that despite dry samples the saturated ones experience $V_{P}$ reduction in the high range of $V_{P-0}$ values. Nevertheless, the magnitude is smaller than what happens in the low $V_{P-0}$ range. Therefore, the main difference between the behavior of the dry and saturated samples is that in the dry ones weathering process has nearly no effect on the $V_{P}$ values, when $V_{P-0}$ is high. However, under saturated testing conditions, weathering process reduced measured $V_{P}$ values in the whole range of initial P-wave velocities. However, the smaller the initial $V_{P-0}$ values, the greater the recorded $V_{P}$ ones after weathering process.

Figures 20 and 21 show uniaxial compressive strength changes after experiencing different freezethaw cycles against initial UCS values respectively for dry and saturated conditions. The obtained data points and relevant fitted trend lines are below 1:1 lines in all plots and therefore weathering decreases the values of measured UCS under all conditions. The fitted trend lines on all plots of Figures $\mathbf{2 0}$ and $\mathbf{2 1}$ have the following general form:

$U C S_{k}=a_{k} U C S_{0}+b_{k} \quad(\mathrm{k}=2,4,8$, and 16$)$

Where $U C S_{k}$ is the uniaxial compressive strength after the $k$-th weathering cycle (MPa), UCS $S_{0}$ is the initial uniaxial compressive strength before experiencing freeze-thaw cycles $(\mathrm{MPa})$, and $a_{k}$ and $b_{k}$ are regression constants. The values of $a_{k}$ and $b_{k}$ along

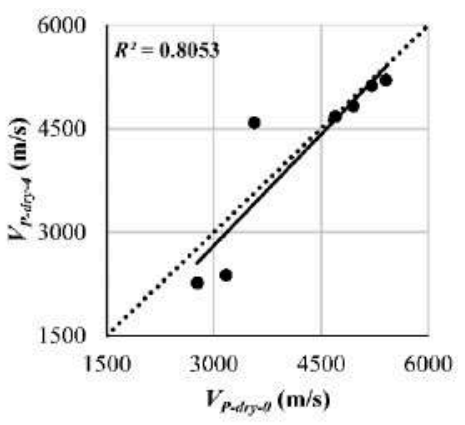

(b)

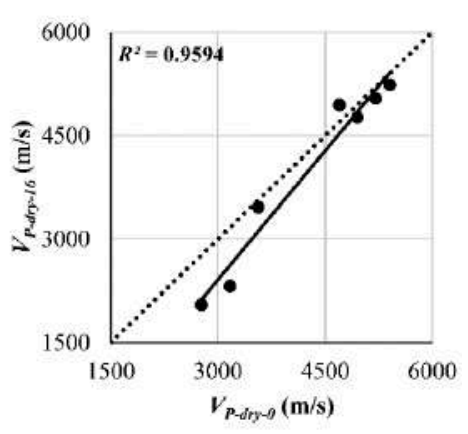

(d)

Figure 18: The variations of $P$-wave velocity values versus initial $P$-wave velocity values $\left(V_{P \text {-dry- } 0}\right)$ for the different tested rock samples after a) two, b) four, c) eight, and d) sixteen freeze-thaw cycles (dry conditions). 


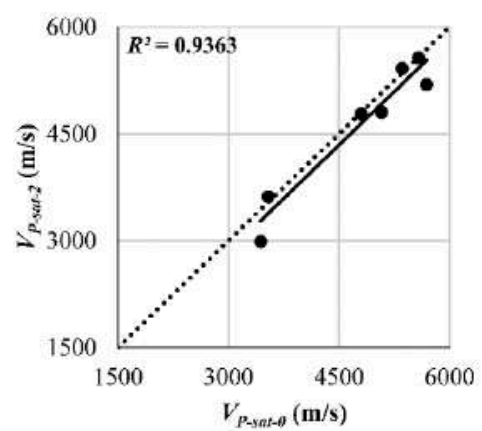

(a)

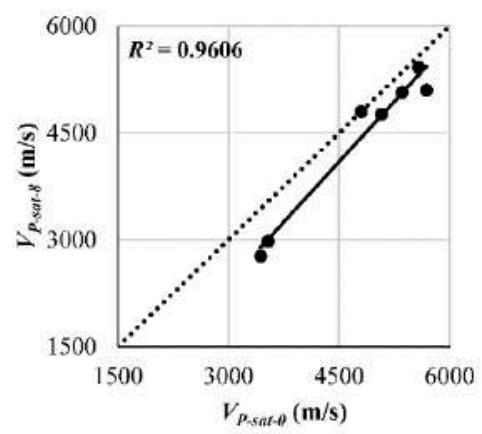

(c)

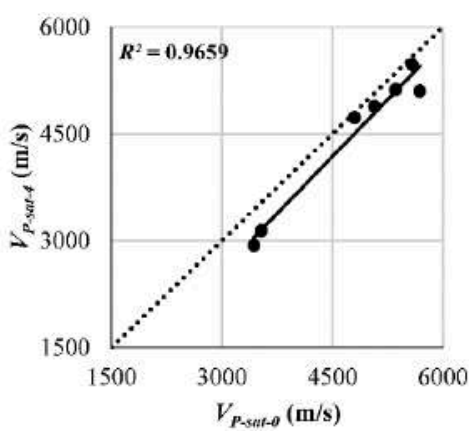

(b)

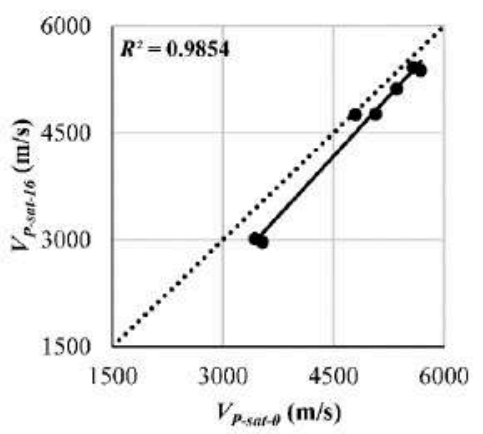

(d)

Figure 19: The variations of $P$-wave velocity values versus initial $P$-wave velocity values $\left(V_{P \text {-sat- } 0}\right)$ for the different tested rock samples after a) two, b) four, c) eight, and d) sixteen freeze-thaw cycles (saturated conditions).

with the relevant correlation coefficients are summarized in Table 2. Comparing the fitted trend lines to plotted 1:1 lines reveals that the effect of freezingthawing cycles is different on the various tested rock types. Under dry conditions and for $k=2$ (Figure 20a), the data points corresponding to low $U C S_{0}$ ranges are closer to the 1:1 line. However, increasing the initial UCS values of tested samples increases the distance between the fitted trends and 1:1 lines. Except for Figure 21a, the general trends on the plots of Figures 20 and 21 are the same. Therefore, it can be said that in stronger rock types, the effect of weathering cycles on the reduction of the measured UCS values is greater than the weaker ones. In other words, the higher the initial UCS values, the higher the decrease of UCS values after freeze-thaw cycles.

In the graphs of Figures 22 and 23, the variations of elastic modulus against the relevant initial values are plotted for different weathering cycles respectively under dry and saturated conditions. As can be seen from the plots, freeze-thaw cycles reduce the measured elastic modulus values. The fitted trend lines in all plots of Figures $\mathbf{2 2}$ and $\mathbf{2 3}$ can be expressed with the following equation:

$E_{l}=a_{l} E_{0}+b_{l} \quad(1=2,4,8$, and 16$)$

Where $E_{l}$ and $E_{0}$ are elastic moduli respectively after 1 -th weathering cycle and before exposing to freezing-thawing process (GPa), $a_{l}$ and $b_{l}$ are constant coefficients which are summarized in Table 2. Except for Figure 23a, which has a relatively low correlation coefficient, the fitted trend lines on the rest of the plots are more or less parallel to 1:1 lines. In other words, the tested rock types with different $E_{0}$ values exhibit nearly the same decrease in $E_{l}$ values after experiencing weathering cycles. The distance of the fitted trend lines to $1: 1$ lines increases gradually in Figures 22a, b, c, and $\mathbf{d}$. The same behavior can be seen in Figure 23d when it is compared to Figures 23a, b, and c. This effect is the result of progressive weathering. As the freeze-thaw cycle counts increase, the relevant measured $E_{l}$ values exhibit greater amounts of decrease.

Figures 24 and 25 show the changes in Brazilian tensile strength values against the initial relevant ones during different weathering cycles and respectively for dry and saturated conditions. Again, the fitted trend lines on the obtained data points have the following linear format:

$B T S_{m}=a_{m} B T S_{0}+b_{m} \quad(\mathrm{~m}=2,4,8$, and 16)

Where $B T S_{m}$ and $B T S_{0}$ are Brazilian tensile strength values respectively after the $m$-th weathering cycle and before exposing to freezing-thawing process (MPa), $a_{m}$ and $b_{m}$ are constant coefficients which are summarized in Table 2. Comparing the results obtained under dry and saturated conditions respectively in Figures $\mathbf{2 4}$ and $\mathbf{2 5}$ reveals that the behavior of dry samples is different from saturated ones as they are exposed to freeze-thaw process. In 


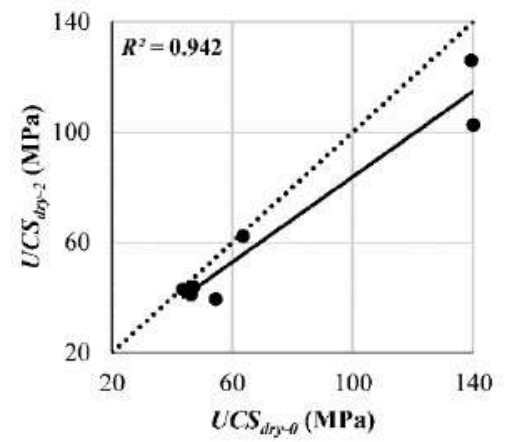

(a)

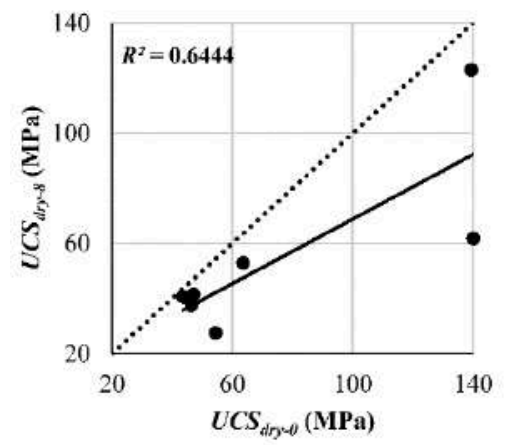

(c)

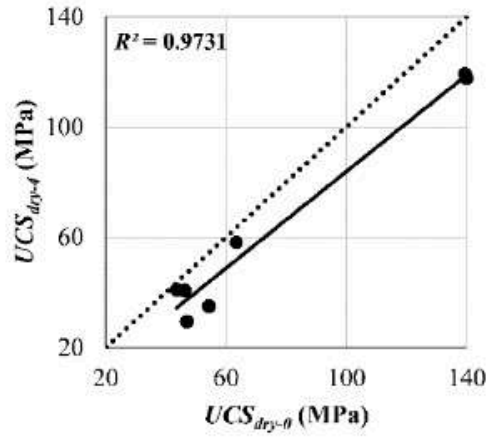

(b)

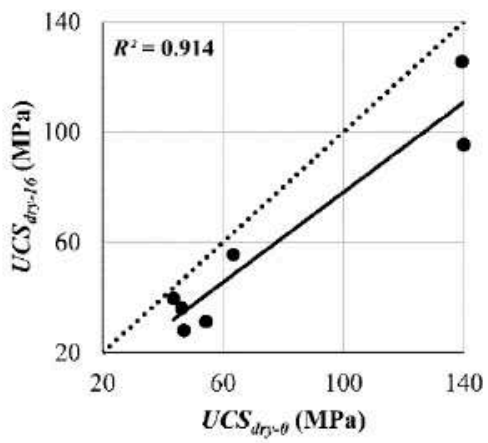

(d)

Figure 20: The variations of uniaxial compressive strength values versus initial uniaxial compressive strength (UCS $\left.S_{d r y-0}\right)$ for the different tested rock samples after a) two, b) four, c) eight, and d) sixteen freeze-thaw cycles (dry conditions).

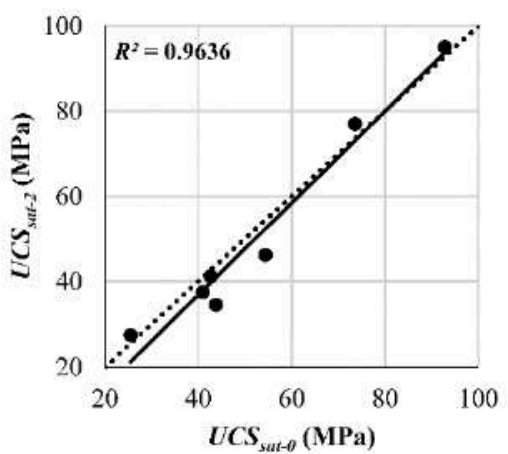

(a)

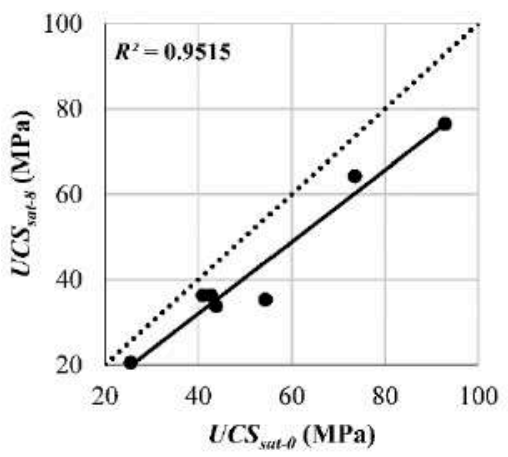

(c)

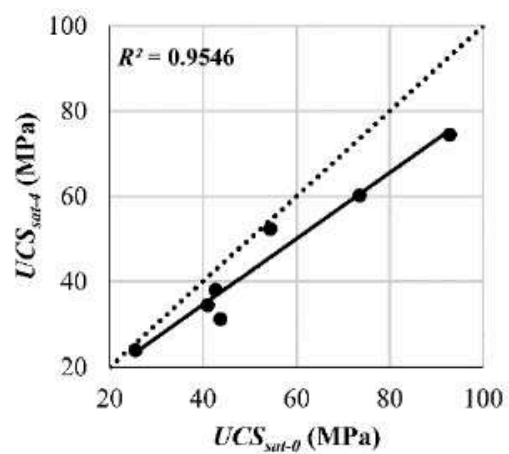

(b)

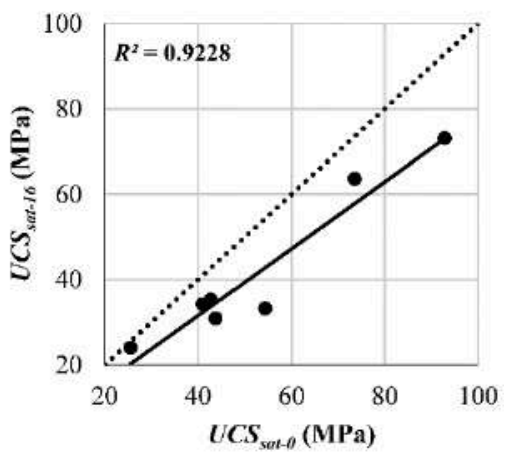

(d)

Figure 21: The variations of uniaxial compressive strength values versus initial uniaxial compressive strength $\left(U C S_{\text {sat }-0}\right)$ for the different tested rock samples after a) two, b) four, c) eight, and d) sixteen freeze-thaw cycles (saturated conditions) 


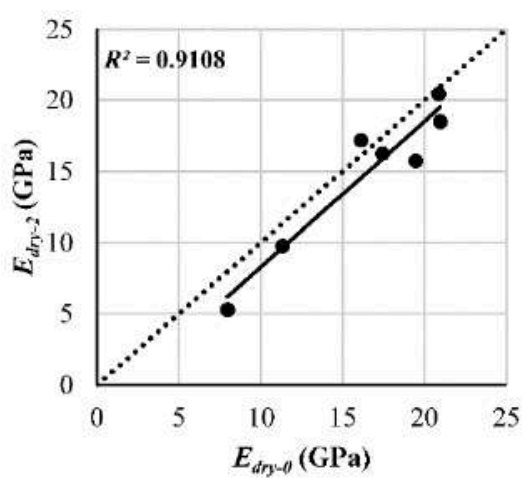

(a)

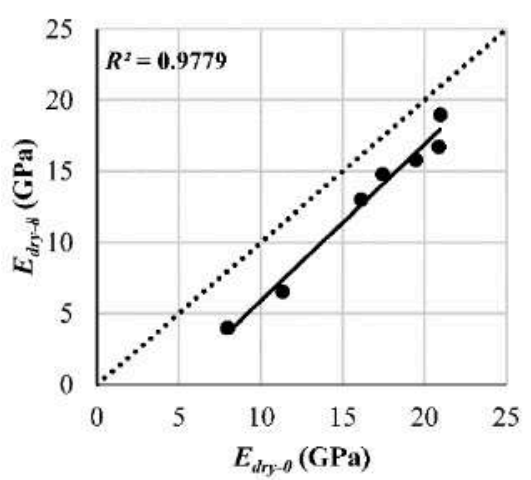

(c)

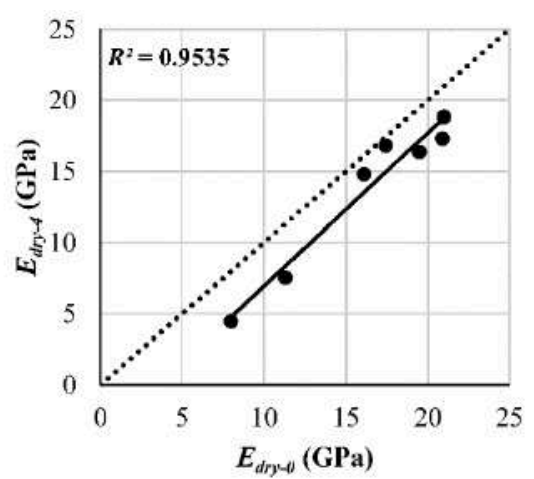

(b)

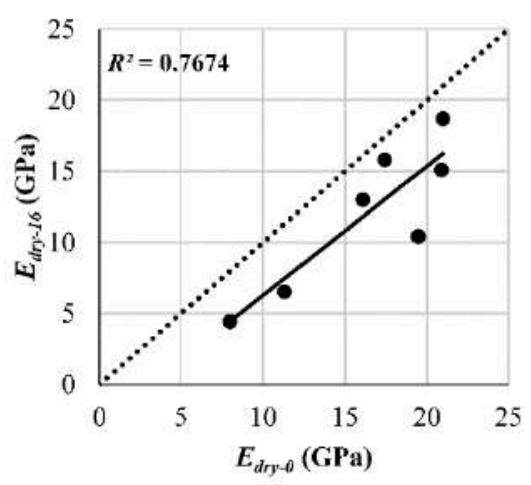

(d)

Figure 22: The variations of elastic modulus values versus initial elastic modulus $\left(E_{d r y-0}\right)$ for the different tested rock samples after a) two, b) four, c) eight, and d) sixteen freeze-thaw cycles (dry conditions).

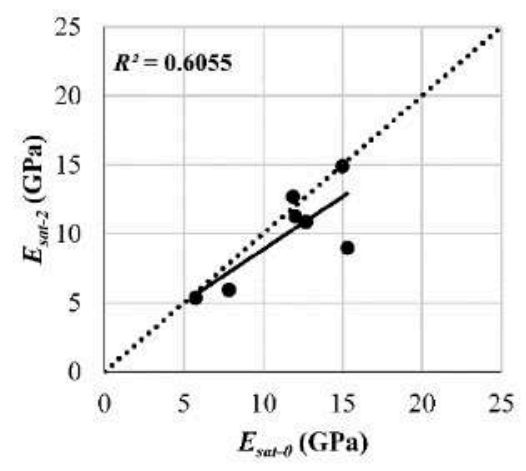

(a)

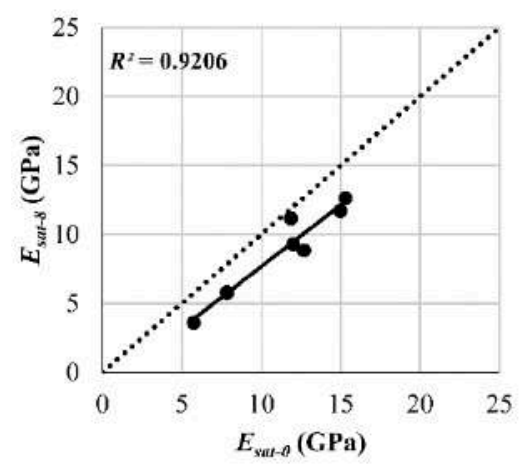

(c)

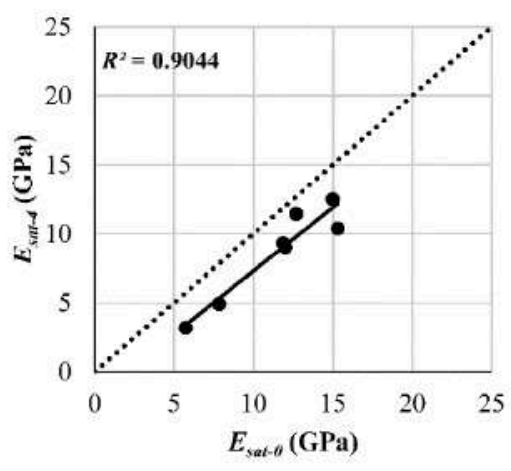

(b)

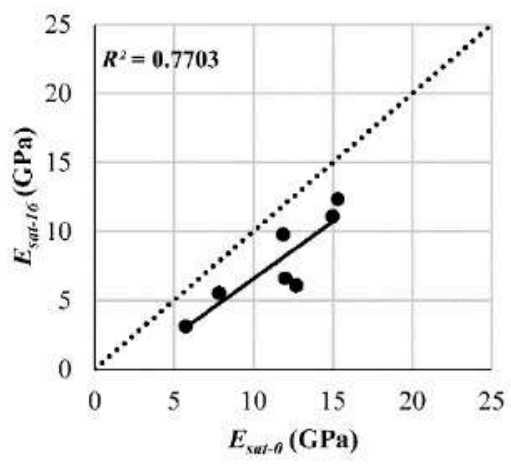

(d)

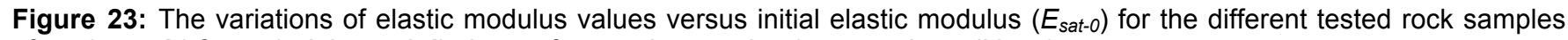
after a) two, b) four, c) eight, and d) sixteen freeze-thaw cycles (saturated conditions). 


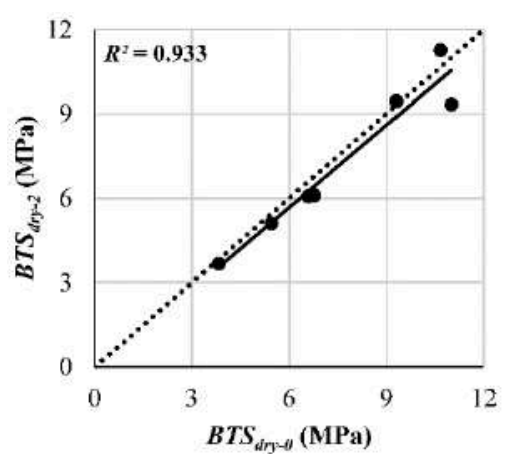

(a)

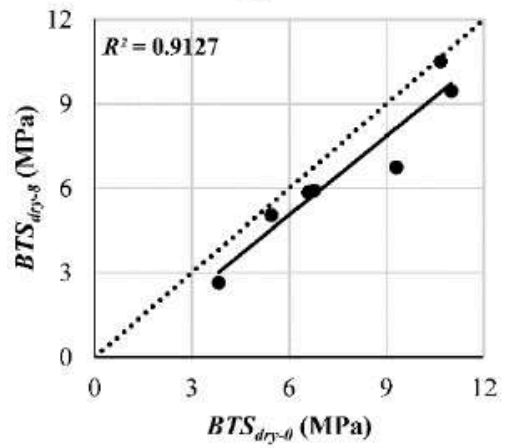

(c)

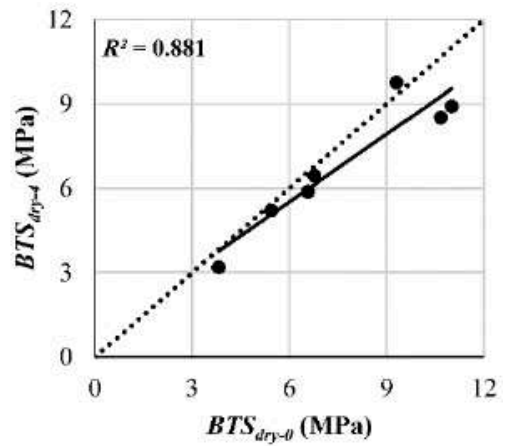

(b)

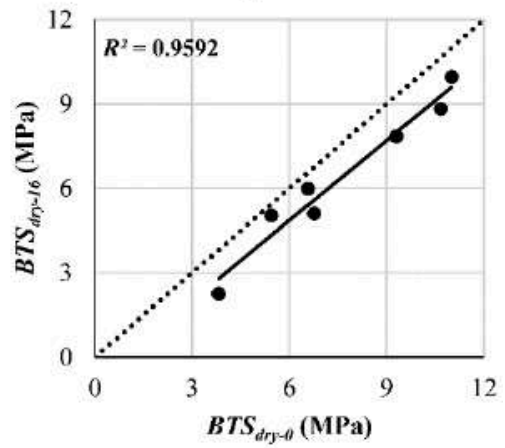

(d)

Figure 24: The variations of Brazilian tensile strength values versus initial Brazilian tensile strength $\left(B T S_{d r y-0}\right)$ for the different tested rock samples after a) two, b) four, c) eight, and d) sixteen freeze-thaw cycles (dry conditions).

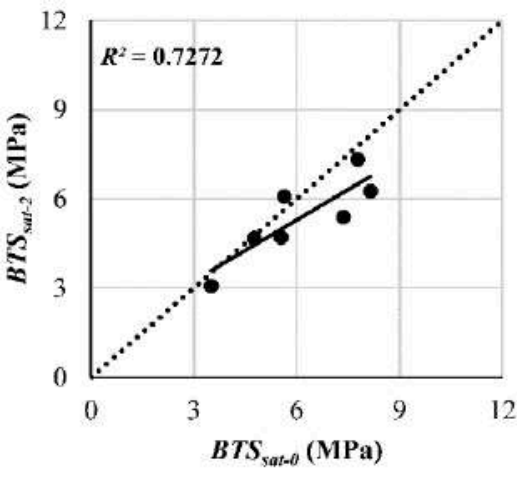

(a)

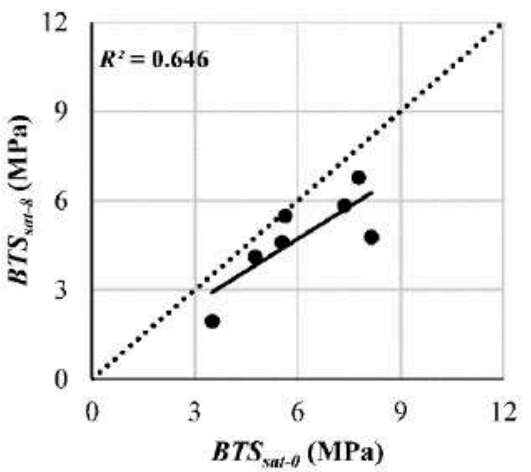

(c)

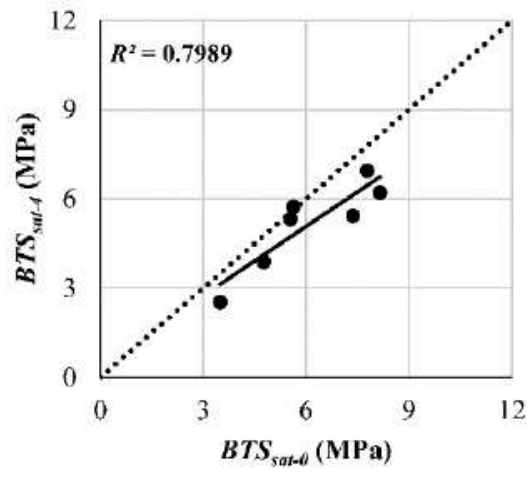

(b)

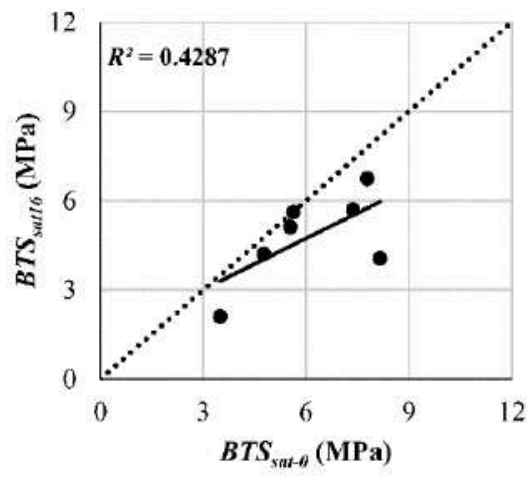

(d)

Figure 25: The variations of Brazilian tensile strength values versus initial Brazilian tensile strength $\left(B T S_{\text {sat- } 0}\right)$ for the different tested rock samples after $\mathbf{a}$ ) two, b) four, c) eight, and $\mathbf{d}$ ) sixteen freeze-thaw cycles (saturated conditions). 
Table 3: The Values of Constant Parameters and Relevant Correlation Coefficients for Predicting Equations under Dry Condition

\begin{tabular}{|c|c|c|c|c|}
\hline Property & $\boldsymbol{A}_{\boldsymbol{i}}$ & $\boldsymbol{B}_{\boldsymbol{i}}$ & $\boldsymbol{C}_{\boldsymbol{i}}$ & $\boldsymbol{R}^{\mathbf{2}}$ \\
\hline \hline $\boldsymbol{n}(\boldsymbol{i}=\mathbf{1})$ & -0.087 & 1.205 & 0.067 & 0.905 \\
\hline $\boldsymbol{V}_{\boldsymbol{p}(\boldsymbol{i}=\mathbf{2})}$ & -658.675 & 1.140 & -17.470 & 0.927 \\
\hline $\boldsymbol{U C S}(\boldsymbol{i}=\mathbf{3})$ & 7.420 & 0.810 & -0.923 & 0.875 \\
\hline $\boldsymbol{E}(\boldsymbol{i}=\mathbf{4})$ & -1.267 & 1.020 & -0.242 & 0.910 \\
\hline $\boldsymbol{B T S}(\boldsymbol{i}=\mathbf{5})$ & 0.256 & 0.932 & -0.071 & 0.929 \\
\hline
\end{tabular}

Table 4: The Values of Constant Parameters and Relevant Correlation Coefficients for Predicting Equations under Saturated Condition

\begin{tabular}{|c|c|c|c|c|}
\hline Property & $\boldsymbol{A}_{\boldsymbol{i}}{ }^{\prime}$ & $\boldsymbol{B}_{\boldsymbol{i}}{ }^{\prime}$ & $\boldsymbol{C}^{{ }^{\prime}}$ & $\boldsymbol{R}^{\mathbf{2}}$ \\
\hline \hline $\boldsymbol{V}_{\boldsymbol{p}}(\boldsymbol{i}=\mathbf{2})$ & -436.198 & 1.064 & -15.325 & 0.957 \\
\hline $\boldsymbol{U C S}(\boldsymbol{i}=\mathbf{3})$ & 3.282 & 0.895 & -0.677 & 0.933 \\
\hline $\boldsymbol{E}(\boldsymbol{i}=\mathbf{4})$ & 0.454 & 0.877 & -0.190 & 0.819 \\
\hline $\boldsymbol{B T S}(\boldsymbol{i}=\mathbf{5})$ & 1.112 & 0.743 & -0.069 & 0.699 \\
\hline
\end{tabular}

the dry samples (Figure 24), the fitted trend lines are parallel to 1:1 lines (except for Figure 24b). This means that when the samples are tested under dry conditions, the different rock types with various initial tensile strength values exhibit the same reduction on the measured tensile strength values due to the effect of weathering cycles. The outcome of testing under saturated conditions (Figure 25) is thoroughly different. In this set of samples, the distance of fitted trend lines to $1: 1$ lines increases when $B T S_{0}$ values increase. This means that the effect of freeze-thaw cycles on the reduction of $B T S_{m}$ values is greater in the samples which have greater initial tensile strength.

To have a more practical mean to predict the effect of mechanical weathering process on the different physical and mechanical properties of various rock types, multivariate regression analyses were performed on the obtained experimental data. For these analyses, the initial values of physical and mechanical properties before experiencing weathering cycles along with the count of weathering cycles were considered as independent variables. The measured physical and mechanical parameters in the weathered rock samples were considered as the dependent variable. The data points obtained in dry and saturated conditions were used separately in the regression analyses. Therefore, separate equations were proposed for dry and saturated conditions. The results of multivariate regression analyses revealed that simple linear equations can effectively predict the changes of physical and mechanical properties during weathering process. The obtained equations can be expressed as follows:

$$
\begin{aligned}
& n=A_{1}+B_{1} n_{0}+C_{1} N \\
& V_{P}=A_{2}+B_{2} V_{P-0}+C_{2} N \\
& V_{P-s a t}=A_{2}{ }^{\prime}+B_{2}{ }^{\prime} V_{P-s a t-0}+C_{2}{ }^{\prime} N \\
& U C S=A_{3}+B_{3} U C S_{0}+C_{3} N \\
& U C S_{\text {sat }}=A_{3}{ }^{\prime}+B_{3}{ }^{\prime} U C S_{\text {sat }-0}+C_{3}{ }^{\prime} N \\
& E=A_{4}+B_{4} E_{0}+C_{4} N \\
& E_{\text {sat }}=A_{4}{ }^{\prime}+B_{4}{ }^{\prime} E_{\text {sat }-0}+C_{4}{ }^{\prime} N \\
& B T S=A_{5}+B_{5} B T S_{0}+C_{5} N \\
& B T S_{\text {sat }}=A_{5}{ }^{\prime}+B_{5}{ }^{\prime} B T S_{\text {sat }-0}+C_{5}{ }^{\prime} N
\end{aligned}
$$

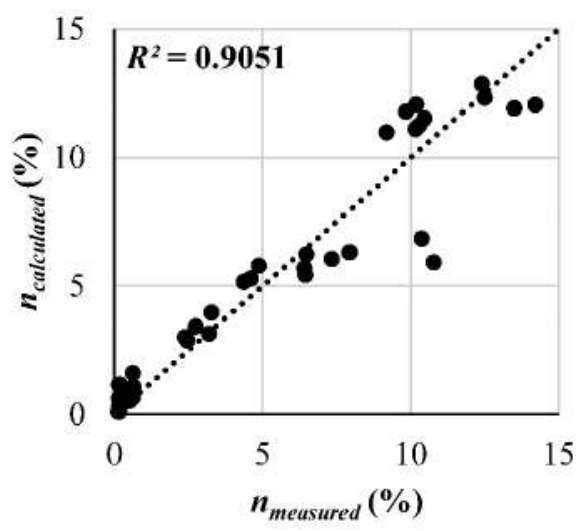

Figure 26: The calculated porosity values against the measured ones.

Where $A_{i}, A_{i}{ }^{\prime}, B_{i}, B_{i}{ }^{\prime}, C_{i}$, and $C_{i}{ }^{\prime}$ are constant regression values and $N$ is the count of weathering cycles. The constant regression values along with the relevant correlation coefficient amounts are 


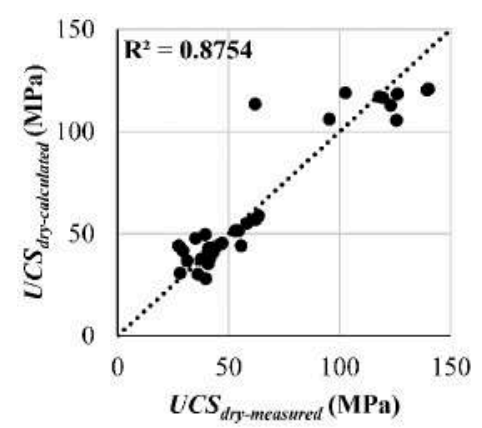

(a)

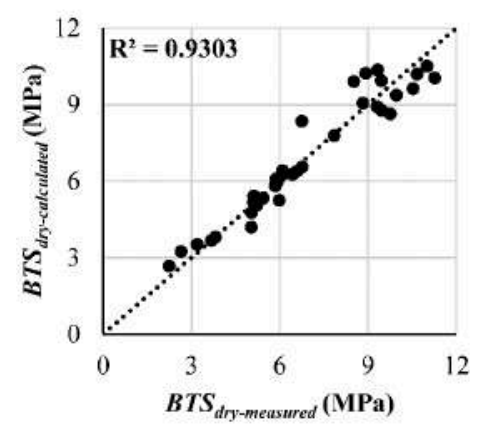

(c)

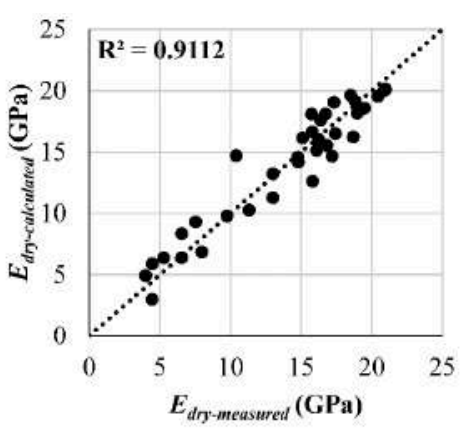

(b)

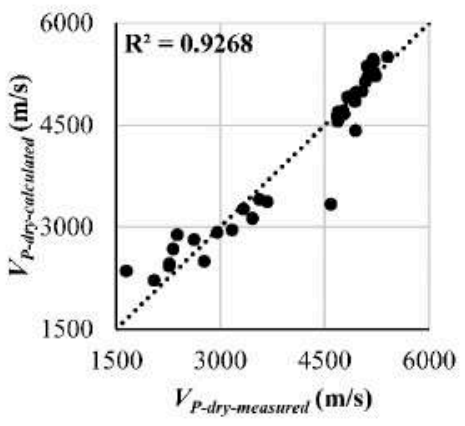

(d)

Figure 27: The calculated values against the measured ones for the different physical and mechanical properties of a) uniaxial compressive strength, b) elastic modulus, c) Brazilian tensile strength, and d) P-wave velocity (dry rock samples).

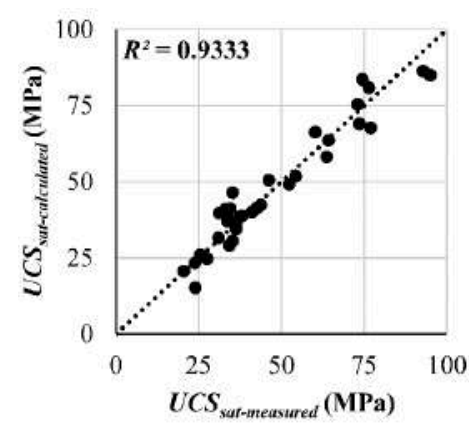

(a)

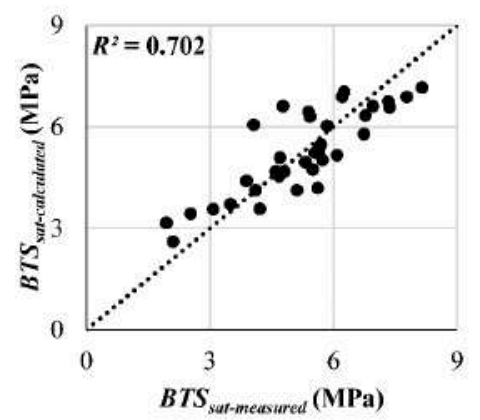

(c)

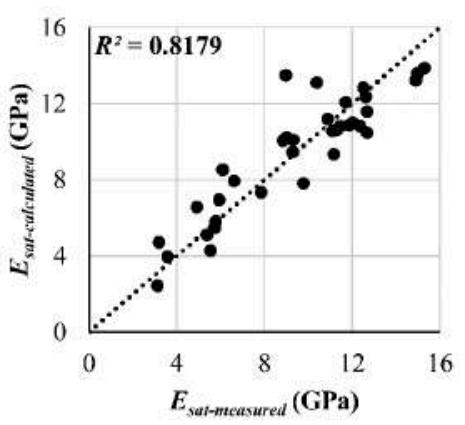

(b)

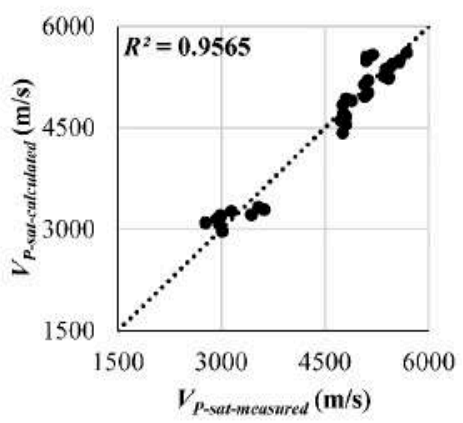

(d)

Figure 28: The calculated values against the measured ones for the different physical and mechanical properties of a) uniaxial compressive strength, b) elastic modulus, c) Brazilian tensile strength, and d) P-wave velocity (saturated rock samples).

summarized in Tables 3 and $\mathbf{4}$ respectively for dry and saturated conditions. In Figure 26, the calculated porosity values from Equation (7) are plotted against measured values. Similarly, in Figures $\mathbf{2 7}$ and $\mathbf{2 8}$ the calculated properties from Equations (8) to (15) are plotted against the measured ones respectively for dry and saturated conditions. Reviewing Figures 26, 27, and 28 along with considering the reported $R^{2}$ values in Tables 3 and $\mathbf{4}$ reveal that the proposed Equations of
(7) to (15) can predict the physical and mechanical properties with a high level of precision.

Despite the high values of correlation coefficient obtained for Equations (7) to (15), the generalization of these equations to practical engineering projects should be done considering some cautions. Firstly, as Tables $\mathbf{3}$ and $\mathbf{4}$ show, except for $C_{1}$ (relevant to porosity changes) all $C_{i}$ and $C_{i}{ }^{\prime}$ values are negative. This means 
that increasing the value of $N$ (number of weathering cycles) will continuously increase the porosity values and decrease the other predicted values of weathered properties. This is in contrast with the trends on Figures 10 to 16 , which show that the increase of porosity values and the reduction of all other discussed properties almost stops in the ending freeze-thaw cycles. Therefore, for generalizing Equations (7) to (15) to real engineering cases, the ultimate value of $N$ can be considered as 16 . This implies the assumption that the different physical and mechanical parameters does not change more, when $N$ becomes greater than 16 . Considering this reasonable assumption will result in the following simple equations for estimating the effect of mechanical weathering on the changes of input design parameters during the life span of a rock-engineering project:

$$
\begin{array}{ll}
n=1.205 n_{0}+0.985 & {[\%]} \\
V_{P}=1.140 V_{P-0}-938 & {[\mathrm{~m} / \mathrm{s}]} \\
V_{P-\text { sat }}=1.064 V_{P-\text { sat }-0}-681 & {[\mathrm{~m} / \mathrm{s}]} \\
U C S=0.810 U C S_{0}-7.348 & {[\mathrm{MPa}]} \\
U C S_{\text {sat }}=0.895 U C S_{\text {sat }-0}-7.550[\mathrm{MPa}] \\
E=1.020 E_{0}-5.139 & {[\mathrm{GPa}]} \\
E_{\text {sat }}=0.877 E_{\text {sat }-0}-2.586 & {[\mathrm{GPa}]} \\
B T S=0.932 \text { BTS }_{0}-0.880 & {[\mathrm{MPa}]} \\
B T S_{\text {sat }}=0.743 B T S_{\text {sat }-0}+0.008 & {[\mathrm{MPa}]}
\end{array}
$$

Secondly, it should be considered that Equations (16) to (24) provide an estimation of the changes of rock physical and mechanical properties due to freezing and thawing effect during the lifetime of a rock-engineering project under the temperature range of $-32^{\circ} \mathrm{C}$ to $+40^{\circ} \mathrm{C}$. The derived equations does not embrace the effect of other weathering types like chemical weathering or mineralogical changes in rock composition. Moreover, the change of governing temperature range may influence the constant coefficients appeared in the Equations.

\section{CONCLUSION}

In this paper, the effect of freezing-thawing cycles on the physical and mechanical properties of different rock types was investigated. The performed testing program included both dry and saturated conditions. Base on the obtained results:

- Increasing the count of weathering cycles increases the porosity of rock samples. When the initial porosity of tested samples is high, the range of porosity changes is great. Low porosity and strong rock materials exhibit smaller ranges of porosity changes during the freeze-thaw process.

- Increasing the count of freezing-thawing cycles decreases the values of $V_{P}, U C S, E$, and BTS. The range of variation is high in the initial cycles. However, in the end applied weathering process the changing rates decrease and the fitted trends become sub-horizontal.

- A general logistic function can describe the changes of all physical and mechanical properties. The high values of obtained correlation coefficient reveal that the proposed function can predict the property changes with acceptable precision.

- $\quad$ Under the dry condition, when the initial values of $V P$ are high, the effect of weathering cycles on the reduction of $V_{P}$ values is small. Under the saturated condition, the samples with high $V_{P}$ values exhibit some reduction in the measured $V_{P}$ values. However, the higher the $V_{p-0}$ values, the lower the occurred $V_{P}$ reduction.

- $\quad$ The sensitivity of UCS values to freeze-thaw cycles is higher for strong samples. When the initial values of UCS are high, greater reductions occurred after experiencing weathering cycles.

- Weathering cycles decrease the values of elastic modulus. However, it seems that in the range of tested rock types, the effect is more or less the same for all tested rock samples. In other words, comparing to the other discussed properties, the reduction in elastic modulus values is less sensitive to its relevant initial values.

- In the dry sample, the effect of weathering cycles on the reduction of $B T S$ values is more or less the same. However, in the saturated ones, the sensitivity to the counts of freezing-thawing cycles increases when the initial BTS values increase.

- A multivariate linear regression analysis was used to predict the changes of physical and mechanical properties of different rock types due to freezing-thawing effect. It was been shown that with some cautions, the obtained correlations can be generalized for practical cases and can be used to predict the change of rock physical and mechanical properties during the lifetime of rock engineering projects.

- In natural stones/rocks with high porosity, whether dry or saturated, the internal structure 
quickly loses its strength properties and cracks and fractures quickly in cold climates. For this reason, especially in high-rise buildings, in order to prevent the natural stones from falling apart, either the ones with low porosity should be preferred, or first of all the pores should be filled with cement or epoxy resins and then dried, and also must be covered with a waterproof chemical film layer. In addition, natural stones whose surface has been filled need to be maintained at short intervals, and it should be known that surface maintenance costs would be high during their entire life.

\section{FUNDING}

The authors did not receive support from any organization for the submitted work.

\section{CONFLICT OF INTEREST}

The authors declare that they have no known competing financial interests or personal relationships that could have appeared to influence the work reported in this paper.

\section{ACKNOWLEDGEMENT}

The authors would like to express their gratitude to Mr. Hadi Shakeri for his unsparing supports in providing the samples used in the testing program.

\section{REFERENCES}

11] Walder J, Hallet B. A theoretical model of the fracture of rock during freezing. Geological Society of America Bulletin 1985; 96(3): 336-46.

https://doi.org/10.1130/0016-7606(1985)96<336:ATMOTF>2 $.0 . \mathrm{CO} ; 2$

[2] Gambino GF, Harrison JP. Rock engineering design in frozen and thawing rock: current approaches and future directions. Procedia engineering 2017; 191: 656-65. https://doi.org/10.1016/j.proeng.2017.05.229

[3] Luo X, Jiang N, Fan X, Mei N, Luo H. Effects of freeze-thaw on the determination and application of parameters of slope rock mass in cold regions. Cold Regions Science and Technology 2015; 110: 32-7.

https://doi.org/10.1016/j.coldregions.2014.11.002

[4] Chen $Y$, Wu $P, Y u$ Q, Xu G. Effects of freezing and thawing cycle on mechanical properties and stability of soft rock slope. Advances in Materials Science and Engineering 2017. https://doi.org/10.1155/2017/3173659

[5] Neaupane KM, Yamabe T, Yoshinaka R. Simulation of a fully coupled thermo-hydro-mechanical system in freezing and thawing rock. International Journal of Rock Mechanics and Mining Sciences 1999; 36(5): 563-80. https://doi.org/10.1016/S0148-9062(99)00026-1

[6] Sun Y, Zhai C, Qin L, Xu J, Yu G. Coal pore characteristics at different freezing temperatures under conditions of freezing-thawing cycles. Environmental earth sciences 2018; 77(13): 525.

https://doi.org/10.1007/s12665-018-7693-y

[7] Zhang X, Lai Y, Yu W, Zhang S. Non-linear analysis for the freezing-thawing situation of the rock surrounding the tunnel in cold regions under the conditions of different construction seasons, initial temperatures and insulations. Tunnelling and underground space technology 2002; 17(3): 315-25 https://doi.org/10.1016/S0886-7798(02)00030-5

[8] Lai YM, Wu Z, Zhu Y, Zhu L. Nonlinear analysis for the coupled problem of temperature and seepage fields in cold regions tunnels. Cold Regions Science and Technology 1999; 29(1): 89-96. https://doi.org/10.1016/S0165-232X(99)00006-3

[9] Liu H, Yuan X, Xie T. A damage model for frost heaving pressure in circular rock tunnel under freezing-thawing cycles. Tunnelling and Underground Space Technology 2019; 83: 401-8. https://doi.org/10.1016/j.tust.2018.10.012

[10] Zhang S, Lai Y, Zhang X, Pu Y, Yu W. Study on the damage propagation of surrounding rock from a cold-region tunnel under freeze-thaw cycle condition. Tunnelling and Underground Space Technology 2004; 19(3): 295-302. https://doi.org/10.1016/j.tust.2003.11.011

[11] Hall K. A laboratory simulation of rock breakdown due to freeze-thaw in a maritime Antarctic environment. Earth Surface Processes and Landforms 1988; 13(4): 369-82. https://doi.org/10.1002/esp.3290130408

[12] Taber S. Intensive frost action along lake shores [New York] American Journal of Science 1950; 248(11): 784-93. https://doi.org/10.2475/ajs.248.11.784

[13] Chen TC, Yeung MR, Mori N. Effect of water saturation on deterioration of welded tuff due to freeze-thaw action. Cold Regions Science and Technology 2004; 38(2-3): 127-36. https://doi.org/10.1016/j.coldregions.2003.10.001

[14] Binal AD. A new laboratory rock test based on freeze-thaw using a steel chamber. Quarterly Journal of Engineering Geology and Hydrogeology 2009; 42(2): 179-98. https://doi.org/10.1144/1470-9236/08-040

[15] Prick A. Dilatometrical behaviour of porous calcareous rock samples subjected to freeze-thaw cycles. Catena 1995; 25(1-4): 7-20. https://doi.org/10.1016/0341-8162(94)00038-G

[16] Hall K. Evidence for freeze-thaw events and their implications for rock weathering in northern Canada: II. The temperature at which water freezes in rock. Earth surface processes and Landforms 2007; 32(2): 249-59. https://doi.org/10.1002/esp.1389

[17] Matsuoka N. Microgelivation versus macrogelivation: towards bridging the gap between laboratory and field frost weathering. Permafrost and Periglacial Processes 2001; 12(3): 299-313. https://doi.org/10.1002/ppp.393

[18] Hall K. Evidence for freeze-thaw events and their implications for rock weathering in northern Canada. Earth Surface Processes and Landforms: The Journal of the British Geomorphological Research Group 2004; 29(1): 43-57. https://doi.org/10.1002/esp.1012

[19] Mutlutürk M, Altindag R, Türk G. A decay function model for the integrity loss of rock when subjected to recurrent cycles of freezing-thawing and heating-cooling. International journal of rock mechanics and mining sciences 2004; 41(2): 237-44. https://doi.org/10.1016/S1365-1609(03)00095-9

[20] Nicholson DT, Nicholson FH. Physical deterioration of sedimentary rocks subjected to experimental freeze-thaw weathering. Earth Surface Processes and Landforms: The Journal of the British Geomorphological Research Group 2000; 25(12): 1295-307.

https://doi.org/10.1002/1096-9837(200011)25:12<1295::AIDESP138>3.0.CO;2-E

[21] Deng HW, Dong CF, Li JL, Zhou KP, Tian WG, Zhang J. Experimental study on sandstone freezing-thawing damage properties under condition of water chemistry. Applied Mechanics and Materials 2014; 556: 826-32. https://doi.org/10.4028/www.scientific.net/AMM.556-562.826

[22] Mousavi SZ, Tavakoli $H$, Moarefvand $P$, Rezaei $M$ Assessing the effect of freezing-thawing cycles on the results of the triaxial compressive strength test for calc-schist rock. International Journal of Rock Mechanics and Mining Sciences 2019; 123: 104090.

https://doi.org/10.1016/j.ijrmms.2019.104090 
[23] Sun Q, Dong Z, Jia H. Decay of sandstone subjected to a combined action of repeated freezing-thawing and salt crystallization. Bulletin of Engineering Geology and the Environment 2019; 78(8): 5951-64. https://doi.org/10.1007/s10064-019-01490-6

[24] Exadaktylos GE. Freezing-Thawing Model for Soils and Rocks. Journal of materials in civil engineering 2006; 18(2): 241-49.

https://doi.org/10.1061/(ASCE)0899-1561(2006)18:2(241)

[25] Fang W, Jiang N, Luo X. Establishment of damage statistical constitutive model of loaded rock and method for determining its parameters under freeze-thaw condition. Cold Regions Science and Technology 2019; 160: 31-8. https://doi.org/10.1016/j.coldregions.2019.01.004

[26] Zhang H, Yuan C, Yang G, Wu L, Peng C, Ye W, Shen Y, Moayedi H. A novel constitutive modelling approach measured under simulated freeze-thaw cycles for the rock failure. Engineering with Computers 2021; 37(1): 779-92. https://doi.org/10.1007/s00366-019-00856-4

[27] Chen Y, Lin H, Wang Y, Zhao Y. Damage Statistical Empirical Model for Fractured Rock under Freezing-Thawing Cycle and Loading. Geofluids, 2020. https://doi.org/10.1155/2020/8842471

[28] Liu Q, Huang S, Kang Y, Liu X. A prediction model for uniaxial compressive strength of deteriorated rocks due to freeze-thaw. Cold Regions Science and Technology 2015; 120: 96-107. https://doi.org/10.1016/j.coldregions.2015.09.013

[29] Kang Y, Liu Q, Huang S. A fully coupled thermo-hydro-mechanical model for rock mass under freezing/thawing condition. Cold regions science and technology 2013; 95: 19-26.

https://doi.org/10.1016/j.coldregions.2013.08.002

[30] Huang S, Liu Q, Cheng A, Liu Y. A statistical damage constitutive model under freeze-thaw and loading for rock and its engineering application. Cold Regions Science and Technology 2018; 145: 142-50.

https://doi.org/10.1016/j.coldregions.2017.10.015

[31] Binal A, Kasapoglu KE, Sensogut C, Ozkan I. Effects of freezing and thawing process on physical and mechanical properties of Selime ignimbrite outcrops in Aksaray-Ihlara valley. In VI Regional Rock Mechanics Symposium. Turkish National Society for Rock Mechanics, Seljuk University, Konya 2002.

[32] Hale PA, Shakoor A. A laboratory investigation of the effects of cyclic heating and cooling, wetting and drying, and freezing and thawing on the compressive strength of selected sandstones. Environmental \& Engineering Geoscience 2003; 9(2): 117-30. https://doi.org/10.2113/9.2.117

[33] Yavuz H, Altindag R, Sarac S, Ugur I, Sengun N. Estimating the index properties of deteriorated carbonate rocks due to freeze-thaw and thermal shock weathering. International Journal of Rock Mechanics and Mining Sciences 2006; 43(5): 767-75.

https://doi.org/10.1016/j.j.jrmms.2005.12.004

[34] Takarli M, Prince W, Siddique R. Damage in granite under heating/cooling cycles and water freeze-thaw condition. International Journal of Rock Mechanics and Mining Sciences 2008; 45(7): 1164-75. https://doi.org/10.1016/j.jijmms.2008.01.002

[35] Momeni A, Abdilor Y, Khanlari GR, Heidari M, Sepahi AA. The effect of freeze-thaw cycles on physical and mechanical properties of granitoid hard rocks. Bulletin of Engineering Geology and the Environment 2016; 75(4): 1649-56.

https://doi.org/10.1007/s10064-015-0787-9

[36] Liu Q, Xu G, Liu X. Experimental and theoretical study on freeze-thawing damage propagation of saturated rocks. International Journal of Modern Physics B 2008; 22(09n11): 1853-58.

https://doi.org/10.1142/S0217979208047523

[37] Yu J, Chen X, Li H, Zhou JW, Cai YY. Effect of freeze-thaw cycles on mechanical properties and permeability of red sandstone under triaxial compression. Journal of Mountain Science 2015; 12(1): 218-31.

https://doi.org/10.1007/s11629-013-2946-4
[38] Wang P, Xu J, Liu S, Wang H, Liu S. Static and dynamic mechanical properties of sedimentary rock after freeze-thaw or thermal shock weathering. Engineering Geology 2016; 210: $148-57$.

https://doi.org/10.1016/j.enggeo.2016.06.017

[39] Tan X, Chen W, Yang J, Cao J. Laboratory investigations on the mechanical properties degradation of granite under freeze-thaw cycles. Cold Regions Science and Technology 2011; 68(3): 130-38. https://doi.org/10.1016/j.coldregions.2011.05.007

[40] Bayram F. Predicting mechanical strength loss of natural stones after freeze-thaw in cold regions. Cold Regions Science and Technology 2012; 83: 98-102. https://doi.org/10.1016/j.coldregions.2012.07.003

[41] Özbek A. Investigation of the effects of wetting-drying and freezing-thawing cycles on some physical and mechanical properties of selected ignimbrites. Bulletin of Engineering Geology and the Environment 2014; 73(2): 595-609. https://doi.org/10.1007/s10064-013-0519-y

[42] Park J, Hyun CU, Park HD. Changes in microstructure and physical properties of rocks caused by artificial freeze-thaw action. Bulletin of Engineering Geology and the Environment 2015; 74(2): 555-65. https://doi.org/10.1007/s10064-014-0630-8

[43] Ghobadi MH, Babazadeh R. Experimental studies on the effects of cyclic freezing-thawing, salt crystallization, and thermal shock on the physical and mechanical characteristics of selected sandstones. Rock Mechanics and Rock Engineering 2015; 48(3): 1001-16. https://doi.org/10.1007/s00603-014-0609-6

[44] Jia H, Xiang W, Krautblatter M. Quantifying rock fatigue and decreasing compressive and tensile strength after repeated freeze-thaw cycles. Permafrost and Periglacial processes 2015; 26(4): 368-77.

https://doi.org/10.1002/ppp.1857

[45] Li J, Kaunda RB, Zhou K. Experimental investigations on the effects of ambient freeze-thaw cycling on dynamic properties and rock pore structure deterioration of sandstone. Cold Regions Science and Technology 2018; 154: 133-41. https://doi.org/10.1016/j.coldregions.2018.06.015

[46] Ni X, Shen X, Zhu Z. Microscopic characteristics of fractured sandstone after cyclic freezing-thawing and triaxial unloading tests. Advances in Civil Engineering 2019. https://doi.org/10.1155/2019/6512461

[47] Cao RH, Wang C, Yao R, Hu T, Lei D, Lin H, Zhao Y. Effects of cyclic freeze-thaw treatments on the fracture characteristics of sandstone under different fracture modes: laboratory testing. Theoretical and Applied Fracture Mechanics 2020; 109: 102738.

https://doi.org/10.1016/j.tafmec.2020.102738

[48] Fener M, Ince I. Effects of the freeze-thaw (F-T) cycle on the andesitic rocks (Sille-Konya/Turkey) used in construction building. Journal of African Earth Sciences 2015; 109: 96-106.

https://doi.org/10.1016/j.jafrearsci.2015.05.006

[49] İnce İ, Fener M. A prediction model for uniaxial compressive strength of deteriorated pyroclastic rocks due to freeze-thaw cycle. Journal of African Earth Sciences 2016; 120: 134-40. https://doi.org/10.1016/j.jafrearsci.2016.05.001

[50] Kolay E. Modeling the effect of freezing and thawing for sedimentary rocks. Environmental Earth Sciences 2016; 75(3): 210.

\section{https://doi.org/10.1007/s12665-015-5005-3}

[51] Fu H, Zhang J, Huang Z, Shi Y, Chen W. A statistical model for predicting the triaxial compressive strength of transversely isotropic rocks subjected to freeze-thaw cycling. Cold Regions Science and Technology 2018; 145: 237-48. https://doi.org/10.1016/j.coldregions.2017.11.003

[52] Ye W, Li C. The consequences of changes in the structure of loess as a result of cyclic freezing and thawing. Bulletin of Engineering Geology and the Environment 2019; 78(3): 2125-38.

https://doi.org/10.1007/s10064-018-1252-3 
[53] Demirdag S. Effects of freezing-thawing and thermal shock cycles on physical and mechanical properties of filled and unfilled travertines. Construction and Building Materials 2013; 47: 1395-1401.

https://doi.org/10.1016/j.conbuildmat.2013.06.045

[54] Mu JQ, Pei XJ, Huang RQ, Rengers N, Zou XQ. Degradation characteristics of shear strength of joints in three rock types due to cyclic freezing and thawing. Cold Regions Science and Technology 2017; 138: 91-7. https://doi.org/10.1016/j.coldregions.2017.03.011

[55] Lei D, Lin H, Chen Y, Cao R, Wen Z. Effect of cyclic freezing-thawing on the shear mechanical characteristics of nonpersistent joints. Advances in Materials Science and Engineering 2019.

https://doi.org/10.1155/2019/9867681

[56] EN-12371, Natural stone test methods-Determination of frost resistance; English version of DIN EN 12371. 2002.
[57] ASTM-D5312/D5312M, Standard Test Method for Evaluation of Durability of Rock for Erosion Control Under Freezing and Thawing Conditions. 2013.

[58] Chuck Muehlbauer CJ. Freeze/thaw cycling in natural stone. Building Stone Magazine 2013. Spring/Summer.

[59] Ulusay R, editor. The ISRM suggested methods for rock characterization, testing and monitoring: 2007-2014. Springer; 2014. https://doi.org/10.1007/978-3-319-07713-0

[60] EN, N., Natural Stone Test Methods Determination of Real Density and Apparent Density, and of Total and Open Porosity. 2008. Ankara: TSE, 1936.

[61] EN-14579, Natural stone test methods-Determination of sound speed propagation. 2006.

Received on 14-11-2021

Accepted on 17-12-2021

Published on 31-12-2021

DOI: https://doi.org/10.31875/2409-9848.2021.08.09

(c) 2021 Hamzaban et al.; Zeal Press

This is an open access article licensed under the terms of the Creative Commons Attribution Non-Commercial License (http://creativecommons.org/licenses/by-nc/3.0/) which permits unrestricted, non-commercial use, distribution and reproduction in any medium, provided the work is properly cited. 